\title{
CHAPTER 2.2.
}

\section{BIOLOGICAL BASIS OF THE STERILE INSECT TECHNIQUE}

\author{
D. R. LANCE ${ }^{1}$ AND D. O. MCINNIS ${ }^{2}$ \\ ${ }^{1}$ USDA/APHIS/PPQ/S\&T CPHST Otis Laboratory, Buzzards Bay, MA 02542, USA \\ Email:dlance@opalakea.com \\ ${ }^{2}$ Deceased
}

\section{TABLE OF CONTENTS}

1. INTRODUCTION............. 114

2. ECOSYSTEM, AGRONOMIC, LIFE HISTORY, AND BIONOMIC CONSIDERATIONS ......... 115

2.1. Role of Pest in Agroecosystems ................................................................................... 115

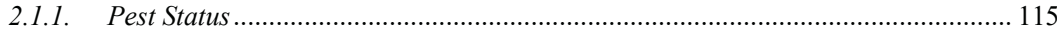

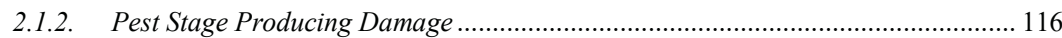

2.1.3. Plant Part Attacked ………………................................................................. 116

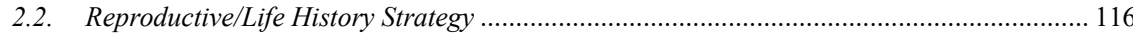

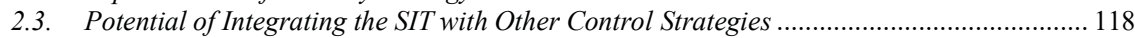

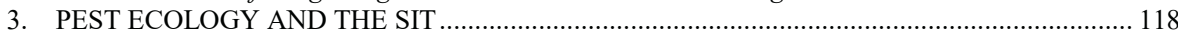

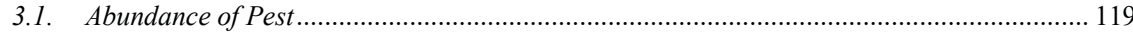

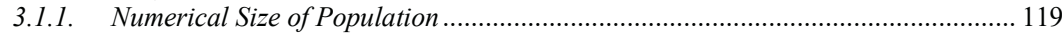

3.1.2. Pest Population Dynamics ............................................................................. 119

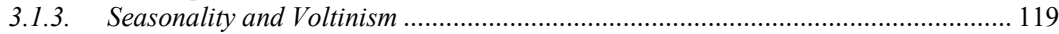

3.2. Dispersion and Dispersal of Wild and Sterile Populations ............................................... 120

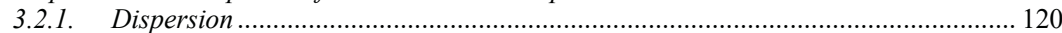

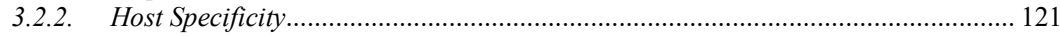

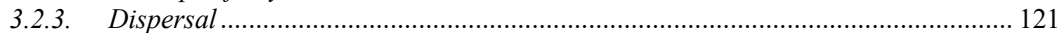

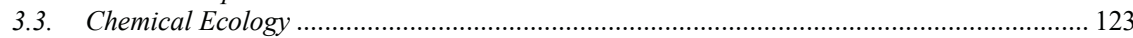

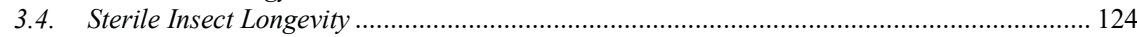

4. BIOLOGY AND STERILE INSECT PRODUCTION ……………………………….................. 124

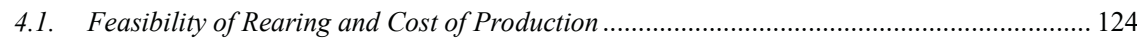

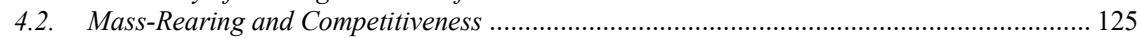

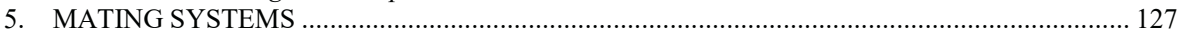

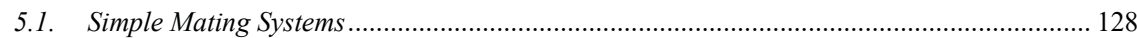

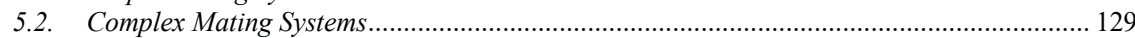

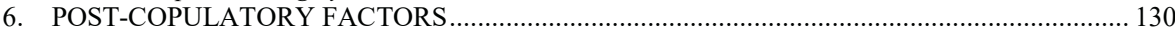

Pages 113-142

V. A. Dyck, J. Hendrichs and A. S. Robinson (eds.), Sterile Insect Technique. Principles and Practice in Area-Wide Integrated Pest Management. Second Edition.

Published with the permission of (C) 2021, US Government. CRC Press, Boca Raton, Florida, USA. 
7. CONCLUSIONS

\section{SUMMARY}

In principle, the sterile insect technique (SIT) is applicable to controlling a wide variety of sexually reproducing insect pests, but biological factors, interacting with socio-economic and political forces, restrict its practical use to a narrower set of pest species and situations. This chapter reviews how the biology and ecology of a given pest affect the feasibility and logistics of developing and using the SIT against that pest insect. The subjects of pest abundance, distribution, and population dynamics are discussed in relation to producing and delivering sufficient sterile insects to control target populations. Pest movement and distribution are considered as factors that influence the feasibility and design of SIT projects, including the need for population- or area-wide management approaches. Biological characteristics, that affect the ability of sterile insects to interact with wild populations, are presented, including the nature of mating systems of pests, behavioural and physiological consequences of mass production and sterilization, and mechanisms that males use to block a female's acquisition and/or use of sperm from other males. An adequate knowledge of the biology of the pest species and potential target populations is needed, both for making sound decisions on the suitability of integrating the SIT into an area-wide integrated pest management (AW-IPM) programme, and on the efficiency and effectiveness of applying the technique.

\section{INTRODUCTION}

In principle, the sterile insect technique (SIT) is simple - the release of a large number of reproductively sterile male insects into a wild population of the same species so that they mate with, and block the reproduction of, wild females (Knipling 1955). Sterility is most often induced by exposing insects to ionizing radiation (Bakri et al., this volume); release of insects with conditionally expressed dominant lethal alleles is increasingly being considered as an alternative and is addressed elsewhere in this volume (Häcker et al., this volume; Lees et al., this volume). Released insects are most often completely sterile (or nearly so), but inherited $\left(F_{1}\right)$ sterility (IS) is an option with species (primarily Lepidoptera) in which appropriate substerilizing doses of radiation produce males that are partially sterile but sire completely sterile offspring (Marec et al., this volume).

The successful application of the SIT requires: (1) the ability to rear, sterilize, and distribute the number of insects that will achieve a sufficiently high "overflooding" (sterile:wild insect) ratio in the field, and (2) that the sterile males can successfully compete and mate with their wild counterparts. Although the concept of the SIT is simple, the implementation is complex (Seawright 1988). Insects are mass-produced in an artificial environment and, after being irradiated, are often densely packed and shipped to a distant facility. Their subsequent release into the field can involve procedures such as immobilization, chilling, and ejection from flying aircraft (Dowell et al., this volume). Through all of this the insects must remain "competitive", i.e. able to survive and perform behaviours that allow them to mate successfully with wild insects (Parker, Vreysen et al., this volume).

Several key biological questions must be considered when deciding whether the use of the SIT would be warranted in a given pest situation (Table 1). Although economic and political considerations may drive decisions on when and where the technique is developed and deployed, these biological issues ultimately determine 
both the logistical feasibility and economics of whether the SIT can contribute to the suppression of a given pest population. Understanding a pest's biology also allows programmes to optimize procedures and avoid pitfalls that could make the SIT impractical or ineffective.

Table 1. Key biological considerations affecting the decision to use the SIT

\begin{tabular}{ll}
\hline \multicolumn{1}{c}{ Question } & \multicolumn{1}{c}{ Biological consideration } \\
\hline Is the pest an appropriate target for the SIT? & $\begin{array}{l}\text { Role of pest in agroecosystems } \\
\text { Existence of negating or complicating trait(s) } \\
\text { Potential of integration into (typically area- } \\
\text { wide) pest management system }\end{array}$ \\
$\begin{array}{ll}\text { Pest ecology and population dynamics } \\
\text { Can adequate sterile:wild ratios be achieved? }\end{array}$ & $\begin{array}{l}\text { Biological factors affecting production, } \\
\text { distribution, and release }\end{array}$ \\
& $\begin{array}{l}\text { Integration with other suppression methods } \\
\text { Eill released sterile males be able to compete }\end{array}$ \\
effectively against wild males in target & $\begin{array}{l}\text { Effect mass-rearing and sterilization on } \\
\text { insect behaviour and physiology }\end{array}$ \\
populations? & $\begin{array}{l}\text { Evolution and the SIT } \\
\text { Pating systems }\end{array}$ \\
& $\begin{array}{l}\text { Post-copulatory factors } \\
\text { competitiveness }\end{array}$ \\
\end{tabular}

\section{ECOSYSTEM, AGRONOMIC, LIFE HISTORY, AND BIONOMIC CONSIDERATIONS}

\subsection{Role of Pest in Agroecosystems}

\subsubsection{Pest Status}

The SIT is mostly used when the selective removal of, or a great reduction in, a population of an individual species would have significant benefit. Examples (not inclusive) of applicable pest situations are shown in Box 1. Alternatively, the SIT would generally not be warranted if the suppression or elimination of a single pest population would not substantially reduce overall management costs or efforts. For example, Ankersmit et al. (1977) concluded that the use of the SIT against the summer fruit tortrix Adoxophyes orana (Fischer von Röslerstamm) in The Netherlands would do little to reduce the number of required insecticide sprays in apple orchards because other tortricid pests are present. 


\subsubsection{Pest Stage Producing Damage}

In his original treatise on the SIT, Knipling (1955) suggested that:

It probably would be impractical to release insects which are highly destructive in the adult stage.

The theoretical basis of the SIT is largely unaffected by which stage(s) produces damage, but sterile insects themselves can be nuisances, disease vectors, or agricultural pests (Nagel and Peveling, this volume). For example, in the case of blood-feeding horn flies Haematobia irritans (L.) (Patterson and Miller 1982), large releases of sterile insects that would affect livestock may preclude the use of the SIT. If the damage from sterile insects is done primarily by females, e.g. mosquitoes, the development of genetic sexing strains can allow the SIT to be used with few or no negative consequences (Seawright 1988; Franz et al., this volume).

Box 1. Examples of Pest Situations Where the SIT Could be Considered for Control

- Incipient population of an non-native pest that, if established, would severely impact agricultural or environmental ecosystems, e.g. eradication of the Mexican fruit fly Anastrepha ludens (Loew) in California, USA (Enkerlin, this volume; Hendrichs, Enkerlin et al., this volume; Hendrichs, Vreysen et al., this volume)

- Vector of a serious disease (plant or animal), e.g. tsetse fly Glossina spp. eradication programmes (Feldmann et al., this volume)

- Presence of a "key pest" that greatly increases management costs and/or is quarantined in potential export markets, e.g. New World screwworm Cochliomyia hominivorax (Coquerel) in North America; Bactrocera spp. in Okinawa (Kuba et al. 1996)

- Alternate methods of controlling a pest disrupt ecological processes that regulate populations of other pests, e.g. chemical control of the boll weevil Anthonomus grandis Boheman disrupts the biological control of noctuids such as Helicoverpa sp.

- Preventing establishment of an important pest by maintaining a continuous population of sterile insects in an area of high risk of introduction, e.g. releases of sterile Mediterranean fruit flies Ceratitis capitata (Wiedemann) in Los Angeles, California, USA (Lance et al. 2014).

\subsubsection{Plant Part Attacked}

In the case of plant pests, the SIT has most often been deployed against insects that attack marketable, especially fruiting, tissues. Small numbers of pests can cause substantial economic damage by attacking these high-value substrates, and, as a technology, the SIT is best used to drive small populations to very low levels or even to local extinction. Similarly, relatively few vectors of plant or animal diseases can be highly damaging. In contrast, many agricultural crops can sustain modest levels of damage to vegetative tissues such as leaves or roots with little or no economic loss, and populations of pests attacking such tissues can, in some cases, be very large (Sutter et al. 1998), and hence the SIT is less appropriate for such pest situations.

\subsection{Reproductive/Life History Strategy}

Since the SIT relies on sterile males mating with wild females, most sexually reproducing insects are at least potential targets of the technique. Beyond that, various aspects of a species' basic biology tend to make that species relatively 
amenable to (Box 2), or a poor candidate for (Box 3), the SIT. Natural parthenogenesis, even at low levels, is a potential pitfall of the SIT, which could theoretically select for parthenogenesis in wild populations (Templeton 1978). Nevertheless, use of the SIT has been considered against facultatively parthenogenetic aphids (Steffan and Kloft 1973). Controlling eusocial insects, such as termites (diplodiploid), with the SIT, while not theoretically impossible, would also present immense challenges in mass-rearing, sterilization, and release. Haplodiploidy, common in Hymenoptera, could make classical deployment of the SIT (rear, sterilize, release) problematic, but could open possibilities for simplified male-only release strategies. Broad taxonomically based generalizations about the applicability of the SIT are risky except, perhaps, that the technique may often be simpler with holometabolous than hemimetabolous insects (Box 2). The presence of the quiescent pupal stage tends to facilitate the harvest, sterilization, and transport of mass-reared insects. Also, larvae of many holometabolous insects have limited mobility and, in some cases, feed gregariously within a restricted unit of habitat such as a fruit. These habits tend to facilitate mass-rearing, whereas in other cases containerization is required to avoid cannibalism. However, the historical bias of area-wide integrated pest management (AW-IPM) programmes integrating the SIT toward Diptera, Lepidoptera, and to a lesser extent Coleoptera, is arguably, as much as anything, a reflection of the large numbers of pest species in these orders. In particular, they contain high percentages of regulatory pests - plant pests and, in the case of Diptera, pests of public and veterinary health concern. Such pests can be prime targets for government-sponsored development of the SIT.

Box 2. Examples of Biological Characteristics that Allow, or Increase the Feasibility of, Using the SIT

- Sexual reproduction (exclusively)

- Methods of mass-rearing are available, or can be developed

- Species is holometabolous (quiescent pupal stage facilitates sterilization and handling)

- Males exposed to sterilizing doses of ionizing radiation can compete with wild males for mates

- Methods are available to monitor released sterile and wild populations

- Low intrinsic rate of increase.

Box 3. Examples of Biological Characteristics that Could Negate or Severely Complicate Using the SIT

- Parthenogenesis

- Highly synchronous, aggregated, ephemeral mating system (found in many eusocial insects and other groups such as some Ephemeroptera)

- Extended life cycle, e.g. typical of many cicadas

- Sterile insects themselves are a serious pest, disease vector, or nuisance pest, such as horn flies, locusts, house flies, cockroaches or female mosquitoes

- Migratory behaviour involving long-distance flight and/or movement along weather fronts, as in various moths, locusts, planthoppers and stable flies. 


\subsection{Potential of Integrating the SIT with Other Control Strategies}

In most applications of the SIT, it is a key component of AW-IPM programmes (Klassen and Vreysen, this volume). As such, the SIT is commonly integrated with other control methods, most often: (1) following pre-release suppression of the target population (often involving insecticides) to the point where the SIT becomes more effective, less costly, or even feasible at all (Knipling 1979), (2) during simultaneous suppression using SIT-compatible controls (for example, the use of larvicides against mosquitoes or screwworms), or (3) exploiting the specificity of the SIT to provide control without disrupting biological control of the target population and/or other species in the area (Knipling 1998). Thus, the potential for area-wide integration of the SIT depends on a species' basic biology, the specific population situation, and the availability of effective and/or compatible suppression tools. Mangan and Bouyer (this volume) discuss supplementary control tactics used in AW-IPM programmes that release sterile insects.

\section{PEST ECOLOGY AND THE SIT}

The successful application of the SIT requires knowledge of the target population's ecology, including estimates of the absolute density of the adult population, and how that density changes over time (Lindquist 1969; Lindquist et al. 1974; Knipling 1979; Itô et al., this volume). For example, the number of insects needed for a given programme depends on the size of the target population, the area covered by the programme, the goal of the programme (Hendrichs, Vreysen et al., this volume), and the required ratio of sterile:wild insects in the field. When Knipling (1955) initially developed the theoretical basis of the SIT, he used a simple mathematical model to demonstrate that a wild population of 1000000 insects could be driven to extinction in 4 or 5 generations by maintaining a level of 2000000 sterile insects within the area (an initial 2:1 overflooding ratio). This model assumed that the wild population was stable, i.e. the average female produced one female offspring that survived to reproduce, and that sterile males were equivalent to wild males in their ability to mate with wild females. In practice, these assumptions are rarely true.

Subsequent models, which contain parameters that incorporate behavioural and ecological information, provide more realistic estimates of overflooding ratios needed for desired levels of suppression (Knipling 1968; Barclay, this volume; Klassen and Vreysen, this volume). In practice, when high rates of increase are involved, the required overflooding ratios can be quite high. Using empirical data, Brower and Tilton (1975) calculated an optimal sterile:wild ratio of about 100:1 for the almond moth Cadra cautella (Walker). In some programmes, ratios greater than 100:1 have not controlled rapidly increasing populations (Vargas et al. 1994; Rendón et al. 2004; Shelly and McInnis 2016). 


\subsection{Abundance of Pest}

\subsubsection{Numerical Size of Population}

The need to produce enough sterile insects to overflood a wild population places practical limits on the size of the target population that can be suppressed or eradicated, and has led to the assertion that the SIT is best applied against relatively small numbers of insects (Knipling 1955, 1979). This can include pests that are widely distributed but tend to occur at low densities, such as the New World screwworm (Knipling 1968), and others that occur in higher densities but exist (at least in the programme area) in relatively small and somewhat isolated patches of habitat. An example of the latter would be populations of Mediterranean fruit flies as they exist in some Middle Eastern areas (Rossler et al. 2000). The SIT has also been used to eradicate highly isolated populations such as the melon fly Zeugodacus cucurbitae (Coquillett) in Okinawa (Kuba et al. 1996), and incipient populations of the Mediterranean fruit fly and the Mexican fruit fly in the United States (Penrose 1996; Lance et al. 2014). For the latter types of programmes, pest surveys must be sensitive enough to detect and delimit a population before it grows beyond the capacity of the system and resources available for eradication (Lance 2014).

\subsubsection{Pest Population Dynamics}

Since the SIT interacts with a pest population at the point of reproduction, overflooding ratios must account for any tendency of the population to increase. As a simple demonstration, Knipling (1968) extended his 1955 model to show that, if a 2:1 overflooding ratio could reduce or eliminate a "stable" pest population, a ratio of 9:1 or $10: 1$, i.e. $2: 1$ X 5 , would be needed for a population that was increasing $5 \mathrm{X}$ per generation. Such rates of increase are not uncommon among insects. For example, Bartlett and Butler (1979) documented a 10-fold increase per generation in pink bollworm Pectinophora gossypiella (Saunders) populations, and Cirio et al. (1972) reported generation-to-generation increases of greater than 40 -fold in the Mediterranean fruit fly. Since rates of increase in the field are difficult to predict, operational programmes should be monitored carefully for effectiveness and to ensure that proper overflooding ratios are being maintained (Knipling 1979). Relationships of pest population dynamics to the SIT are discussed by Barclay (this volume) and Itô et al. (this volume).

\subsubsection{Seasonality and Voltinism}

Pest populations do not continuously increase at high rates. In warmer regions, many insects breed year-round, or at least go through multiple generations annually, but the populations cycle in response to factors such as the abundance of food, e.g. host plants, weather (temperature, wet/dry cycles), and cropping cycles (Adkisson 1971; Wong et al. 1983). Conceptually, seasonal periods of low and declining pest numbers provide opportunities to effectively apply the SIT against pest populations that are too large during other seasons (Knipling 1968; Lindquist 1969; Adkisson 1971; Hendrichs, Vreysen et al., this volume); empirical data support this concept 
(Iwahashi 1976; Baumhover 2002). However, following reductions in target population numbers, maintaining adequate "pressure" from sterile insects on the pest population can be difficult when resources subsequently become abundant and pest populations rapidly increase in size. For example, Carpenter and Gross (1993) were not able to stop season-to-season increases in populations of the corn earworm Helicoverpa zea (Boddie) with releases of substerile males, although they consistently delayed or reduced the extent of those increases. If releasing sufficient sterile insects becomes impractical during some portions of the year, then alternating sequences of the SIT with other methods of pest management, e.g. mass-trapping or cultural control, may prove more cost-effective than continual releases of sterile insects (Cirio 1974; Thomas and Mangan 2005).

Many insect species, especially in temperate areas, have a dormancy period. Dormancy may involve diapause, induced by environmental factors such as photoperiod or temperature, and be either facultative or obligate (Leopold 2007). Temperate species are frequently univoltine (one generation per year); in some, a single generation requires two or more years. Mating, then, is restricted to specific periods within the year, and the production and release of sterile insects must be properly timed to ensure the maximum benefit (Mastro and Schwalbe 1988). If partial sterility carries across generations, conditions that initiate and break diapause in sterile insects must be appropriate, or sterile insects may not be present when needed. As examples, relatively normal diapause characteristics were observed in $H$. zea with inherited $\left(\mathrm{F}_{1}\right)$ sterility and in sterile backcross hybrids of Heliothis subflexa (Guenée) x Heliothis virescens (F.) (tobacco budworm), allowing appropriately timed activity and/or survival over winter (Stadelbacher and Martin 1981; Carpenter and Gross 1989). In multivoltine species with facultative diapause, competitiveness can vary between insects that were reared under diapause-inducing versus nondiapause conditions (Bloem et al. 2006; Sarvary et al. 2008).

\subsection{Dispersion and Dispersal of Wild and Sterile Populations}

Programmes that release sterile insects can be strongly affected by both the dispersion (distribution of organisms over an area) and the dispersal (movement, or displacement, of individuals) of wild and sterile populations. These two parameters are influenced by a variety of ecological and behavioural factors intrinsic to a species' basic biology, and that tend to make that pest species more or less amenable to the implementation of the SIT.

\subsubsection{Dispersion}

Most insect populations have clumped distributions with areas of relatively high density amid regions of substantially lower density. This clumping is often related to the distribution of resources, such as host plants, and may vary seasonally (Shiga 1986). For example, Nakamori and Shiga (1993) outlined zones of Z. cucurbitae density in Okinawa based on the seasonal availability of host fruits, and identified "hot spots" where host fruits were abundant year-round. In such local areas with high densities of wild insects, the overflooding ratio is substantially lower than the 
overall ratio of sterile to wild insects throughout the programme area. As a result, other things being equal, the effectiveness of sterile insect releases would decrease as the degree of clumping in the target population increases (Sawyer et al. 1987; Barclay 1992). This effect will be overcome to the degree that the sterile insects are distributed, or redistribute themselves, to mirror the distribution of the wild insects. The degree to which sterile insects actually do concentrate themselves in areas of high wild insect density has reportedly varied from high (Knipling 1979; Gavriel et al. 2012; Ageep et al. 2014) to low (Shiga 1986; Hendricks et al. 1973; Meats 2007) across diverse taxa. In any case, the distributions of wild and sterile populations must be understood to be able to allocate and distribute sterile insects optimally (Lindquist et al. 1974; Itô et al., this volume). Geographic information (GIS) and database systems can facilitate the identification, monitoring, and differential treatment of population foci on relatively broad spatial scales (Bouyer et al., this volume). However, if the aggregations of target populations occur on finer spatial scales, or are not predictable, the overall release rates may have to be adjusted upwards to ensure that the local sterile:wild ratios are high enough to achieve the desired level of sterility.

\subsubsection{Host Specificity}

The distribution of an insect population will, of course, be influenced by the distribution of its hosts and, as a result, by the pest's degree of monophagy or polyphagy. Plant pests targeted in AW-IPM programmes that use the SIT have ranged from relatively monophagous or oligophagous pests such as the pink bollworm to highly polyphagous pests such as $H$. virescens and $C$. capitata (Proshold et al. 1983; Staten et al. 1999; Liquido et al. 2015; Staten and Walters 2021). Monophagy should tend to simplify the application of the SIT, especially if host plants are restricted to discrete patches. For polyphagous pests, the widespread presence of alternate hosts can increase the area, logistical complexity, and costs required for effective control (Vargas et al. 1995). Movement of insects to and from sites of adult food, or other ecological requisites, can also influence pest distribution (Hendrichs and Hendrichs 1990). For example, adult male New World screwworms, when waiting for potential mates, will often perch near sources of adult food (nectar) rather than near the animals that are the larval hosts (Guillot et al. 1978).

\subsubsection{Dispersal}

The ability of wild insects to move within and between habitat patches influences the required size of release areas, the need for and size of barrier or buffer areas, and the pattern of insect release (Knipling 1979). The immigration of small numbers of mated females or large numbers of males into an SIT release area can potentially disrupt a programme (Prout 1978; Barclay, this volume). The magnitude of the impact from immigration depends on pest biology and on programme goals, with less isolation being required where moderate suppression rather than eradication is desired. For example, Ankersmit et al. (1977) reported that the SIT appeared to be capable of suppressing populations of the summer fruit tortrix in small orchards with a modest degree of isolation, even though the efficacy obtained was not sufficient 
for eradication. The dispersal capacity of a pest species determines the need to isolate treatment areas from immigration, and is the primary factor dictating a population-wide approach to AW-IPM programmes integrating the SIT (Hendrichs, Vreysen et al., this volume; Klassen and Vreysen, this volume).

In eradication programmes, the potential for reinvasion also needs to be considered. The melon fly was eradicated from subtropical Japan (Kuba et al. 1996), but continuous surveys are now needed in the region, with preventive sterile fly releases in the southernmost islands, because this species is capable of flying in from Taiwan (Koyama and Tanaka 1984; Kohama and Kuba 1996). The New World screwworm was eliminated from North America but, because the flies are capable of dispersing more than $280 \mathrm{~km}$, the eradication campaign had to be extended into northern Mexico, covering simultaneously a large area to protect the southern USA. Eventually, these large eradication blocks were progressively moved southward into Central America, where the areas to be covered became gradually narrower, reducing the size and cost of the programme (Lindquist 1969; Jones et al. 1999; McGraw 2001; Vargas-Terán et al., this volume). A wide band of sterile-fly releases across eastern Panama has been in place since the early 2000s to prevent reinvasion from South America. Conversely, when the SIT is used in too small an area against an incipient, isolated infestation, undetected dispersal away from the site of the initial introduction can foil eradication efforts by producing satellite infestations beyond the SIT release zone (Penrose 1996).

Pilot-scale testing of the SIT also requires relatively isolated venues such as islands or oases (Proshold et al. 1983; Cayol and Zarai 1999; Baumhover 2002; Bellini et al. 2013) or, alternately, plots that are buffered with wide barrier or treatment zones (Rendón et al. 2004). Such tests tend to be relatively large-scale, and can produce the added benefit of detecting logistical or biological problems that would not arise in smaller-scale studies (Seawright 1988; McInnis et al. 1996). However, large-scale tests are expensive, and logistical issues often force limits on size and/or replication. As a result, field data on relationships between sterile:wild ratios, sterile insect competitiveness and level of sterility, and effects on wild populations, are minimal in many cases (Krafsur 1998; Vreysen, this volume). In some instances, the initial stages of an operational programme have to function as a feasibility study (Lindquist et al. 1974).

Although long-distance movement can create problems for programmes that apply the SIT, dispersal on a more local scale is essential to the technique's effectiveness. Modelling studies indicate that a moderately high dispersal capability may tend to facilitate the SIT by reducing spatial heterogeneity in the pest population (Barclay and Vreysen 2011; Barclay, this volume). Hence, arthropods that are largely sedentary, such as ticks and mites, as well as various homopterans, are much less amenable to the SIT. Moreover, released sterile males must move sufficiently to locate resources such as food, mating arenas, and/or mates (Parker, Vreysen et al., this volume; Vreysen, this volume). The dispersal capability of sterile males is a primary consideration when designing release methods and protocols for a specific pest species, since it is critical that sterile males are distributed throughout the release area, at least in habitats where wild insects may occur (Andress et al. 2013; Dowell et al., this volume). 


\subsection{Chemical Ecology}

Chemical communication is often involved in mating, feeding, or other key ecological interactions of insects (Matthews and Matthews 2009). Accordingly, an insect's chemical ecology can have important implications for the SIT (Table 2). In particular, the common involvement of semiochemicals in intraspecific finding and/or recognizing mates means that sterile males must respond to, and in some cases produce, semiochemicals appropriately for the SIT to be effective (Table 2). In addition, an insect's chemical ecology can often be exploited to benefit AW-IPM programmes that integrate the SIT. Long-range attractants are very useful for assessing the distribution of wild and sterile insects (section 3.2.1.), monitoring overflooding ratios (Vreysen, this volume), and evaluating specific aspects of sterile male quality (Parker, Vreysen et al., this volume). In addition, males of species that use a long-range female-produced sex attractant are normally mobile enough to disperse well throughout the release area (sections 3.2.1. and 3.2.3.).

In some species, feeding, or otherwise exposing sterile males to an appropriate compound, can optimize mating competitiveness (Pereira et al. 2013; Pereira et al., this volume). Sometimes these chemicals are components (or precursors of components) of male-produced pheromones, which may be long-range sex attractants or close-range "aphrodisiacs" (Boppre 1990; Nishida et al. 1997; Shelly et al. 2010; McInnis et al. 2011). In other cases, reasons for the enhancement are not clear; e.g. mating competitiveness is improved when sterile Mediterranean fruit fly males are exposed to the parapheromone $\alpha$-copaene (Shelly and McInnis 2001).

Table 2. Examples of types of semiochemicals utilized by insects, and their potential implications for programmes releasing sterile insects

\begin{tabular}{ccc}
\hline Type of semiochemical & Implication for programmes & Reference \\
\hline $\begin{array}{c}\text { Sex attractant pheromone } \\
\text { (female-produced) }\end{array}$ & $\begin{array}{c}\text { Used for monitoring or evaluating } \\
\text { programmes that apply the SIT } \\
\text { Used for assessing sterile male quality }\end{array}$ & $\begin{array}{c}\text { Bloem et al. 1998 } \\
\text { Staten et al. 1999 } \\
\text { Staten and Walters 2021 }\end{array}$ \\
$\begin{array}{c}\text { Sex attractant or aggregation } \\
\text { pheromone (male- } \\
\text { produced) }\end{array}$ & $\begin{array}{c}\text { May be critical component of sterile } \\
\text { male competitiveness (section 5) }\end{array}$ & Heath et al. 1994 \\
$\begin{array}{c}\text { Parapheromone (such as the } \\
\text { "male attractants" of } \\
\text { tephritids) or aggregation } \\
\text { pheromone }\end{array}$ & $\begin{array}{c}\text { Used for monitoring or evaluating } \\
\text { programmes that apply the SIT }\end{array}$ & Used for assessing sterile male quality \\
(section 5) & AcInnis and \\
$\begin{array}{c}\text { Aphrodisiac and/or contact } \\
\text { recognition pheromone }\end{array}$ & $\begin{array}{c}\text { May play important role in mating } \\
\text { process and affect mating }\end{array}$ & FAO/IAEA/USDA 2019 \\
& competitiveness (section 5) & Carlson et al. 2007 \\
$\begin{array}{c}\text { Host-plant or other food- } \\
\text { related kairomones }\end{array}$ & $\begin{array}{c}\text { Used for monitoring programmes that } \\
\text { apply the SIT }\end{array}$ & Dominiak and Nicol \\
& $\begin{array}{c}\text { May play critical role in mating system } \\
\text { May need to be provided in diet as }\end{array}$ & Shelly et al. 2010 \\
& precursor of pheromone component & McInnis et al. 2011 \\
& Benelli et al. 2014
\end{tabular}




\subsection{Sterile Insect Longevity}

The frequency of sterile insect releases will depend on each species, and varies according to the average longevity. Preferably, sterile insects will survive in the field as long as their wild counterparts. If the longevity of sterile insects declines, the frequency of releases, and numbers of insects released, must be increased to maintain the desired overflooding ratio (Dowell et al., this volume; Vreysen, this volume). A reduction in longevity can be a side effect of mass-rearing, strain genetics, sterilization, or handling and release methods (Fay and Meats 1987; Meats 1998). Assessment of the longevity of sterile insects has largely been conducted in the laboratory (Meats 1998; Thomas and Loera Gallardo 1998), but over the past decade there has been increasing recognition that survival in the field is critical and is influenced by factors beyond the scope of laboratory tests. For example, released insects can suffer proportionately higher predation than wild insects if release methods concentrate or temporarily immobilize insects, or if mass production alters normal predator-avoidance behaviour (Iwahashi 1976; Hendrichs and Hendrichs 1998; Hendrichs et al. 2007; González-López et al. 2016). The survival of sterile insects to reproductive age is especially critical, but in many programmes immature adults that suffer significant mortality are released before reaching sexual maturity. Ideally, they should not be released into the field until they are sexually mature (McInnis et al. 2013), or at least have acquired nutritional reserves (Dowell et al., this volume), although this increases the required holding capacity. Many SIT programs now recommend periodically measuring survival of released insects in the field as part of their standard quality control protocols (FAO/IAEA/USDA 2019; Parker, Vreysen et al., this volume; Vreysen, this volume).

\section{BIOLOGY AND STERILE INSECT PRODUCTION}

\subsection{Feasibility of Rearing and Cost of Production}

Technical issues surrounding the production of sterile insects are reviewed elsewhere (Parker, Mamai et al., this volume), but some biological factors that influence the feasibility of mass-rearing bear mention here. As noted above, sterile insect production should generally be easier with holometabolous than with hemimetabolous species. Also, dormancy periods must be taken into account when designing rearing systems (Parker, Mamai et al., this volume), and, in some cases, they can be exploited to "stockpile" sterile insects (Mastro and Schwalbe 1988; Bloem et al. 2000; Leopold 2007). In some insects, developing specific components of rearing systems can prove intractable, e.g. the continued lack of useful artificial diets for rearing larvae of some bark beetles (Mattanovich et al. 1999), root-feeding beetles (Branson et al. 1988; Klein and Allsopp 1994), or parasites of mammals such as Dermatobia hominis (L., Jr.) (Banegas et al. 1967; Arce 1968; Borja 2002).

The cost of rearing insects, in particular, affects the economic feasibility of the SIT (Mumford, this volume), and is influenced by basic biological characteristics. Small insects with rapid life cycles can often be reared relatively cheaply. For example, Mediterranean fruit flies develop from the egg to prepupal stage in 6-9 
days within large trays of relatively inexpensive diet, and several thousand sterile flies can be produced for USD 1 (Hendrichs et al. 2002). At that rate, tens of thousands of Mediterranean fruit flies can be produced for the current cost of rearing a single individual of the Asian longhorned beetle Anoplophora glabripennis (Motschulsky), a 3-cm-long cerambycid with a 10-month larval period (Dubois et al. 2002). Developmental and operational costs of mass-rearing can also increase with cannibalism, which can require individual containerization, provision of refugia and/or reduced rearing density (Da Silva and Parra 2013; Fontenot et al. 2015). Some insects also need specialized environments, such as artificial streams for simuliid larvae (Edman and Simmons 1985). In many cases, innovation and automation help to reduce costs and other problems of mass-production (Parker, Mamai et al., this volume). Finally, while lower reproductive rates generally reduce overall SIT costs by requiring lower overflooding ratios in the field, they tend to increase the unit rearing cost because facilities needed to maintain such colonies (tsetse species are an extreme case) are large relative to production output (Hendrichs, Vreysen et al., this volume).

\subsection{Mass-Rearing and Competitiveness}

A sterile male's ability to compete for mates against wild males is a function of its phenotype, which, as in all living organisms, is determined by the expression of its genotype within its environment. Insects in mass-rearing facilities typically experience biotic and physical environments that clearly are very different from those in which wild insects develop. These environmental differences can influence the phenotype of sterile insects both directly and, along with other factors, by inadvertently selecting for genetic differences between laboratory and wild populations. Careful monitoring of phenotype (manifest as sterile insect quality) is critical to the success of programmes that use the SIT (Parker, Vreysen et al., this volume; Vreysen, this volume).

Many aspects of mass-rearing environments directly affect sterile insect quality. Characteristics of artificial larval or adult diets, such as nutritive elements, contaminants, microbial load (including probiotics), moisture, texture, and $\mathrm{pH}$ can influence body size, survival, longevity, flight ability, mating ability, and responsiveness to light (Economopoulos et al. 1990; Villavaso et al. 1998; Chang et al. 2000; Damiens et al. 2012; Yuval et al. 2013); in some cases effects can extend to the following generation (Keena et al. 1998). Handling methods and environmental conditions that optimize, or are simply convenient for, mass-rearing do not always produce the most competitive insect. A classic example is the "droopy-wing syndrome" and poor flight ability that were found to occur in tephritid flies when pupae were sifted from the pupation medium during the time of flight muscle development (Ozaki and Kobayashi 1981). Lance et al. (1988) reported another example where holding Lymantria dispar (L.) pupae at typically warm laboratory temperatures "programmed" sterile males with inappropriately timed mating activity. Conversely, temperature preconditioning (cold-conditioning) enhanced the survival and mating success of sterile male Queensland fruit flies Bactrocera tryoni 
(Froggatt) (Fay and Meats 1987). More details on rearing methodology and insect quality are presented by Parker, Mamai et al. (this volume) and Parker, Vreysen et al. (this volume).

Reproductive sterility is typically induced by exposure to X-rays, electron beams, or gamma rays from a ${ }^{60} \mathrm{Co}$ or ${ }^{137} \mathrm{Cs}$ source (LaChance 1975; Bakri et al., this volume; Robinson, this volume), which all cause chromosomal damage. Sterility is usually permanent, although irradiated males of some species may, over time, regain at least partial fertility, especially following multiple mating (Brower 1976). Nevertheless the irradiation process typically reduces insect quality in some measurable way. Various strategies minimize somatic damage and thus preserve quality: irradiating insects near, or after the completion of, adult development, i.e. late-stage pupae or adults, irradiation in a reduced-oxygen atmosphere, "fractionating" the dose into several smaller doses, and using irradiators with small maximum to minimum dose ratios (which allow the minimum sterilizing dose to be achieved without substantially overdosing a large proportion of the insects) (Economopoulos 1977; ISO/ASTM 2013; Bakri et al., this volume; Parker, Vreysen et al., this volume).

Radiation doses that sterilize males typically kill oogonial cells, but the radiation sensitivity of oocytes varies with such factors as maturity and meiotic stage. As a result, females of some species may retain a degree of fertility after irradiation, especially when treated late in development. For example, in C. capitata, careful monitoring is needed to ensure that pupae are not irradiated too early, resulting in poor quality, or too late, leaving some females with residual fertility (Williamson et al. 1985). Some insect species that are irradiated as adults, such as the boll weevil, require alternative or augmentative sterilization strategies (McKibben et al. 2001).

Chemical sterilization, symbiont-based cytoplasmic incompatibility (CI), and incorporation of conditionally lethal genes are among the alternative methods of generating mass-reared insects for genetic control programs (Augustinos et al., this volume; Häcker et al., this volume; Hendrichs and Robinson, this volume; Robinson, this volume). In particular, advances in molecular biology have facilitated the production of strains for release of insects carrying a dominant lethal (RIDL), which can potentially be applied using either a bisexual or self-perpetuating sexlinked (males only) approach (Hendrichs and Robinson, this volume). RIDL, as well as Wolbachia-based CI, have been advanced furthest for mosquitos (Alphey 2014; Augustinos et al., this volume; Lees et al., this volume), but both have been under development for other taxa as well (Zabalou et al. 2009; Morrison et al. 2012; Leftwich et al. 2014; Häcker et al., this volume).

Chemosterilization was considered a viable alternative to radiation early in the development of the SIT (LaBrecque and Smith 1968), but was largely abandoned due to the potential of chemical residues on the sterile insects that can have mutagenic effects on non-targets (including humans). Much safer insect chemosterilants are now available but their use to date has been proposed primarily for field application (autodissemination) rather than SIT production (e.g. Moya et al. 2010).

Mass-rearing can also produce genetic differences between wild and laboratory populations (Cayol 2000). Indeed, dramatic shifts in strain genetics, including reductions in diversity (heterozygosity), can be observed within a relatively few 
generations under laboratory conditions (Zygouridis et al. 2014). Genetic changes in rearing colonies have been cited as the likely causes of shifts in such traits as flight ability, mating age, age at first reproduction, cuticular hydrocarbons, and adult longevity (Spates and Hightower 1970; Itô and Koyama 1982; Pomonis and Mackley 1985; Hammack 1987; Mangan 1991; Miyatake and Shimizu 1999; Suenaga et al. 2000; Meats et al. 2004). Mating arenas, in particular, may differ greatly between field and laboratory environments, and inadvertent selection of inappropriate mating behaviours in mass-reared colonies could be especially detrimental to the SIT (Edman and Simmons 1985; Briceño and Eberhard 1998; Shelly 2012). Strategies for maintaining the competitiveness of mass-reared strains include holding colonies under "relaxed" conditions to minimize selection of undesirable traits, regular replacement of mass-reared strains, and active selection for desirable traits such as mating compatibility with wild strains (Leppla et al. 1983; McInnis et al. 1985; McInnis et al. 2002; Orozco-Davila et al. 2014; Bosa et al. 2016; Quintero-Fong et al. 2016). Of course, suboptimal genetics in mass-reared strains can result from factors other than inadvertent selection, such as genetic drift associated with "bottlenecking" or even less-than-ideal traits in the insects that were used to found the colony.

\section{MATING SYSTEMS}

Given that population suppression by the SIT is overwhelmingly a function of matings between sterile males and wild females (McInnis et al. 1994), the ability of released sterile males to compete for mates is critical. The mating competitiveness of sterile males is a function of their mating propensity and mating compatibility. Mating propensity, the tendency to locate a mate, copulate and inseminate, is primarily of concern as a component of sterile insect quality (Parker, Vreysen et al., this volume). Mating compatibility is a relative measure of how readily two populations of insects are reproductively compatible, and, in relation to the SIT, most often refers specifically to matings of sterile males with wild females (FAO/IAEA/USDA 2019). Parker, Vreysen et al. (this volume) describe methods of assessing and quantifying compatibility. In programmes that release sterile insects, it is necessary to ensure that those insects are compatible with the target insect population (FAO 1992; Cayol et al. 2002).

Insect mating systems are almost as diverse as the insects themselves, and have been categorized in a variety of ways, such as their relation to ecological resources (Hendrichs et al. 2002), type or degree of aggregation, the type or extent of malemale competition (Robacker et al. 1991; Hendrichs et al. 2002), means by which females select mates (Eberhard 1996), or the involvement and type of semiochemicals. Insects use a variety of sensory modalities to locate, identify, and evaluate potential mates and related resources, including vision, sound, odours, contact chemoreception, and "touch" (Matthews and Matthews 2009).

For the SIT, the modalities used in an insect's mating system have to be understood. Sterile males must be competent in their ability to communicate with females, as receiver and/or sender of signals, to be fully competitive (Table 3). Most 
mating systems, in themselves, do not preclude the use of the SIT, but they influence the efficiency and logistical difficulty of the technique. In general, greater levels of complexity in the role of the male in mating will require more effort in tracking male behaviour as a part of product quality control (Hendrichs et al. 2002; Parker, Mamai et al., this volume), and will lower expectations of high mating competitiveness of mass-produced sterile males (Shelly and McInnis 2016).

Table 3. Characteristics of insect mating systems that are favourable or less favourable for the development and operation of programmes releasing sterile insects

\begin{tabular}{lll}
\hline Characteristic of mating system & \multicolumn{1}{c}{ Favourable } & Less favourable \\
\hline $\begin{array}{l}\text { Behavioural role of male, } \\
\text { including any courtship ritual }\end{array}$ & Simple & Complex \\
Female choice of mates & Passive (accepts first male) & $\begin{array}{c}\text { Active (chooses among } \\
\text { males) }\end{array}$ \\
Sex pheromone & $\begin{array}{c}\text { Female-produced, simple (1- or } \\
\text { 2-component), long-range }\end{array}$ & $\begin{array}{c}\text { Male-produced, complex } \\
\text { Characteristics of adult male }\end{array}$ \\
Long-lived, active disperser & $\begin{array}{c}\text { Short-lived, sedentary } \\
\text { Contest for mates or } \\
\text { resources }\end{array}$ \\
Mating in time and space & Indirect (scramble for mates) & $\begin{array}{c}\text { Highly aggregated, e.g. } \\
\text { termite swarms }\end{array}$ \\
\hline
\end{tabular}

\subsection{Simple Mating Systems}

Relatively simple mating systems often involve scramble competition for females. For example, adult female gypsy moths emerge essentially mature, do not feed, and begin "calling" (releasing a single-component sex attractant) near their pupation sites, which are spread throughout their habitat. To mate successfully, a male moth must be active at the time of day when females begin calling (Lance et al. 1988), be capable of locating the source of the pheromone (before another male finds it), and then recognize and attempt copulation with a female when he, literally, steps on her (Charlton and Cardé 1990). Mating is slightly more complex in the New World screwworm where male flies must locate and perch in sites where they can encounter flying females (Guillot et al. 1978). The males dart out and grab at small objects flying by, recognizing and attempting to mate with females if a contact pheromone is present (Hammack 1992). Such relatively simple mating systems are amenable to the SIT, and can lead to the production of highly competitive sterile males. Sterile male gypsy moths are typically nearly $100 \%$ competitive, based on their ability to locate pheromone sources (Mastro 1978), and on the relationship of induced egg sterility to the ratios of sterile:wild males trapped during pilot tests 
(Mastro and Schwalbe 1988; Simmons et al., this volume). One downside of simple mating systems, especially those with pure scramble competition, is that they are often associated with short adult lifespans and compressed mating periods (sections 3.4. and 3.1.3.).

\subsection{Complex Mating Systems}

The difficulty of producing highly competitive sterile males will, as a general rule, increase with the complexity of the males' mating-related behaviours (Shelly and McInnis 2016). For example, Mediterranean fruit fly males attract females by releasing a very complex pheromone (Jang et al. 1989) from an appropriate microhabitat, which typically, but not always, is the underside of a sun-lit leaf. Males often call near other calling males at locations that have been referred to as leks (Prokopy and Hendrichs 1979). When a female approaches a male, he initiates a complex courtship ritual and, if the female remains to the end of the display, he attempts to mount her. Following mounting the female can mate, or reject the male by dropping from the leaf (Lance et al. 2000). Given the complexity of male behaviour, differences in pheromone composition and sexual behaviour between wild and sterile male Mediterranean fruit flies are not unexpected (section 4.2.), and in fact have been quantified (Heath et al. 1994; Briceño and Eberhard 1998; Shelly 2012; Vaníčková et al. 2012). Accordingly, in small-scale mating assays through pilot-scale tests, sterile male Mediterranean fruit flies have usually been less than fully competitive, and in very extreme cases less than $1 \%$ competitive (Wong et al. 1986; McInnis et al. 1994, 1996; Rendón et al. 2004). Such lapses in mating competitiveness can increase costs, and compromise the effectiveness of programmes that release sterile insects (Parker, Vreysen et al., this volume; Vreysen, this volume; Whitten and Mahon, this volume). In spite of this, the SIT is increasingly being used against the Mediterranean fruit fly and other tephritids in suppression, eradication, containment and prevention contexts (Rossler et al. 2000; Lance et al. 2014; Enkerlin, this volume; Hendrichs, Vreysen et al., this volume). Several potential methods of enhancing the competitiveness of sterile Mediterranean fruit flies have been investigated, such as optimizing pre-release feeding regimes (Yuval et al. 2007, 2013) and hormonal treatments (Pereira et al. 2013). "Aromatherapy", the pre-release treatment of adults with semiochemicals (section 3.3.), has been shown consistently to enhance Mediterranean fruit fly mating competitiveness, and is now an integral part of the operating procedures at most fly emergence and release facilities (Shelly and McInnis 2001; Dowell et al., this volume; Pereira et al., this volume).

The mating behaviour of sterile males becomes especially critical when females, as in the example above, actively choose among mates based on male phenotype. In these insects, seemingly minor differences in behaviour between wild and sterile insects can translate into poor competitiveness (Lance et al. 2000). In addition, selection can potentially favour wild females that are adept at identifying and rejecting sterile males, resulting in wild populations that are "behaviourally resistant" to the SIT (Itô et al., this volume; Whitten and Mahon, this volume). 
Apparently, this occurred after several years of sterile insect releases against $C$. capitata on the island of Kauai, Hawaii, USA - the percentage of successful courtships dropped from about $10 \%$ to 1 or $2 \%$ for interactions between sterile males and wild females; however, the compatibility of the sterile males with wild females from other islands was unaffected (McInnis et al. 1996; Lance et al. 2000). A similar erosion of mating compatibility had previously been noted and overcome during the SIT-based successful eradication of Z. cucurbitae in Japan (Hibino and Iwahashi 1991).

\section{POST-COPULATORY FACTORS}

The effectiveness of mating between sterile males and wild females can be lost partially or entirely if the females also mate with wild males, and preferentially use sperm from the latter for fertilization. To determine if the SIT is appropriate for use against an insect species, Knipling (1955) proposed that one principle to consider was:

Females must normally mate only once.

This assertion is still occasionally voiced dogmatically, at least as a question, although polyandry does not negate the basic principles of the technique (Barclay, this volume; Whitten and Mahon, this volume). However Knipling (1955) continued:

\footnotetext{
If females of a species mate more frequently, the sperms from irradiated (sterile) males must be produced in essentially the same number and compete with sperms from fertile males.
}

Indeed, all else being equal, the overall sterility induced into a population of ten females by a sterile:wild overflooding ratio of 9:1 should be the same whether each female mates once - nine with a sterile male and one with a wild male - or each female mates ten times - nine times with sterile males and once with a wild male. This issue is broader than Knipling's assertions, but regardless of the number of times that a female "normally" mates, the competitiveness of sterile males will be influenced by post-mating factors, including the ability to induce mating refractoriness in females, sperm competition, and/or sperm precedence, depending on the species.

Patterns of female receptivity include variations on three basic themes: (1) monogamy, (2) females cycle through periods where they alternately are or are not receptive, and (3) continuous receptivity (Ringo 1996). In most insects, female receptiveness drops sharply after mating, typically due to a physiological response to materials passed from male to female during copulation (LaChance 1975; Eberhard 1996; Ringo 1996; Kraaijeveld et al. 2005). In many species the sperm or spermatophores themselves produce the effect, but in others (best documented among dipterans) an "anti-aphrodisiac" in the seminal fluid - often an accessorygland protein - produces the change (Ringo 1996). An accessory-gland factor has been documented in C. capitata, and males from sterile and wild strains were found 
equally competent at inducing females to shift from mate-seeking to oviposition behaviours (Jang et al. 1998); similarly, sterile and wild Anastrepha fraterculus (Wiedemann) were found to be comparable in rendering females refractory to further mating (Abraham et al. 2013). Female Z. cucurbitae became unreceptive after mating either with virgin or with "spermless" (sperm-depleted) males (Kuba and Itô 1993), and female Anopheles gambiae Giles became refractory after mating with males that were rendered spermless by RNAi silencing of a germ cell differentiation gene (Thailayil et al. 2011).

In other species, the transfer of a full complement of sperm appears to be the critical factor that turns off female receptiveness. For programmes for these other species, this requires that sterility be based on dominant lethal mutations rather than, for example, on the elimination of sperm production (LaChance 1975). Male lepidopterans produce sperm that are apyrene (anucleate) as well as eupyrene (functional), and in particular the presence of eupyrene sperm appears to be important in shutting off receptivity (LaChance 1975). Radiation doses that cause reproductive sterility can also reduce the quantity and/or quality of a male's sperm (North et al. 1975; LaChance et al. 1979; Proshold et al. 1993). Also, sperm are often depleted faster (after fewer matings) in radiation-sterilized males than in unirradiated males (Haynes and Mitchell 1977). The $F_{1}$ sterile progeny of substerilized males may also transfer less than a full complement of sperm (Carpenter et al. 1987; Proshold et al. 1993; Marec et al., this volume). Sterilizationrelated reductions in the amount of sperm transferred to females can reduce sterile male competitiveness by increasing the incidence of remating among females that mate with both sterile and wild males (Haynes and Mitchell 1977; Carpenter et al. 1987).

When females mate with both sterile and wild males, the proportion of eggs fertilized by the sperm of sterile males can be influenced by the species' patterns of sperm precedence and/or the competitiveness of the males' ejaculates. In many species sperm from recent matings takes precedence over sperm from earlier matings (Brower 1975; Etman and Hooper 1979), although other species show firstmating (El Agoze et al. 1995) or variable sperm precedence (Conner 1995; LaMunyon and Huffman 2001). In some species sperm precedence is complete, or nearly so (Brower 1975; Etman and Hooper 1979), and specialized mechanisms exist to expel or otherwise inactivate sperm from previous matings (Waage 1979). However, often sperm from different matings mix to various degrees, and the proportion of offspring a male sires will depend at least in part on the competitiveness of his ejaculate. The Mediterranean fruit fly shows a general sperm precedence for more recent matings (Saul and McCombs 1993), but sperm from earlier matings is conserved and may become more available as fresher sperm is depleted (Scolari et al. 2014).

Ejaculate competitiveness can potentially be related to a variety of factors such as male age (LaMunyon 2001), but often the determinant is simply the quantity or quality of sperm transferred (Saul and McCombs 1993; Alyokhin and Ferro 1999; LaMunyon and Huffman 2001). The proportion of a multiple-mated female's eggs that any given male fertilizes can be reduced by sterilization procedures (LaMunyon 2001). This effect has been shown to be dose-dependent in the fall armyworm 
Spodoptera frugiperda (J.E. Smith) (Carpenter et al. 1997), and influenced by the age at irradiation in the boll weevil (Villavaso et al. 1998).

\section{CONCLUSIONS}

No insect is a "perfect" target for the SIT. Sterile Mediterranean fruit flies can be produced in large numbers at a reasonable cost, but the high release rates required, and the complex role of the male in mating, can create problems for operational programmes. New World screwworm flies have a relatively simple mating system but are not easy to rear, and in a mass-production situation the quality of a colony tends to degrade rapidly (Mangan 1991). Although numbers of tsetse required for release are much lower than for other species, it is also problematic to rear them in sufficient numbers (Opiyo et al. 2000). In spite of these problems, the SIT is being used successfully against all of these insects in AW-IPM programmes that, in some cases, are among the most extensive insect management programmes ever undertaken.

For other insects, such as the boll weevil and gypsy moth, functional SIT technology has been developed but is not being used (at least not on a significant scale) because simpler or more cost-effective alternative control methods are available. Agronomic, socio-economic, and biological factors must be weighed when deciding whether the SIT is an appropriate tool for managing a given pest. One generalization that probably can be made regarding pest biology and the SIT is this: when considering, developing, or conducting an AW-IPM programme integrating the SIT, an understanding of the pest's biology is critical to making appropriate decisions and to the overall success of the programme.

\section{REFERENCES}

Abraham, S., M. C. Liendo, F. Devescovi, P. A. Peralta, V. Yusef, J. Ruiz, J. L. Cladera, M. T. Vera, and D. F. Segura. 2013. Remating behavior in Anastrepha fraterculus (Diptera: Tephritidae) females is affected by male juvenile hormone analog treatment but not by male sterilization. Bulletin of Entomological Research 103: 310-317. DOI: 10.1017/S0007485312000727 https://www.ncbi.nlm.nih.gov/pubmed/23340454

Adkisson, P. L. 1971. Weak-links in the population dynamics and diapause of Heliothis zea (Boddie) which might be exploited by the sterile-insect release technique, pp. 355-362. In Proceedings, Symposium: Sterility Principle for Insect Control or Eradication. International Atomic Energy Agency and Food and Agriculture Organization of the United Nations, 14-18 September 1970, Athens, Greece. STI/PUB/265. IAEA, Vienna, Austria.

https://www.iaea.org/sites/default/files/18/03/1_new_spinconerad71-cvr-1-2-full.pdf

Ageep, T. B., D. Damiens, B. Alsharif, A. Ahmed, E. H. O. Salih, F. T. A. Ahmed, A. Diabate, R. S. Lees, J. R. L. Gilles, and B. B. El Sayed. 2014. Participation of irradiated Anopheles arabiensis males in swarms following field release in Sudan. Malaria Journal 13: 484. http://www.malariajournal.com/content/13/1/484

Alphey, L. 2014. Genetic control of mosquitoes. Annual Review of Entomology 59: 205-224. https://doi.org/10.1146/annurev-ento-011613-162002

Alyokhin, A. V., and D. N. Ferro. 1999. Electrophoretic confirmation of sperm mixing in mated Colorado potato beetles (Coleoptera: Chrysomelidae). Annals of the Entomological Society of America 92: 230-235. https://doi.org/10.1093/aesa/92.2.230 
Andress, E., I. Walters, M. del Toro, and T. Shelly. 2013. Release-recapture of sterile male Mediterranean fruit flies (Diptera: Tephritidae) in southern California. Proceedings of the Hawaiian Entomological Society 45: 11-29. http://hdl.handle.net/10125/31000

Ankersmit, G. W., C. J. A. Barel, J. D. Mobach, I. Schout Parren, G. Wassenberg de Vries, G. W. De Vries, and I. S. Parren. 1977. Studies on the sterile male technique as a means of control of Adoxophyes orana (Lepidoptera: Tortricidae). 5. Release trials. Netherlands Journal of Plant Pathology 83: 73-83.

Arce, A. A. 1968. Possibilities for using the sterile-male technique in torsalo, Dermatobia hominis, and other livestock pests in the OIRSA area, pp. 1-3. In Proceedings, Panel: Control of Livestock Insect Pests by the Sterile-Male Technique. Joint FAO/IAEA Division of Atomic Energy in Food and Agriculture, 23-27 January 1967, Vienna, Austria. STI/PUB/184. IAEA, Vienna, Austria. https://www.iaea.org/sites/default/files/sit-livestock-pest-control.pdf

Banegas, A. D., H. Mourier, and O. H. Graham. 1967. Laboratory colonization of Dermatobia hominis (Diptera: Cuterebridae). Annals of the Entomological Society of America 60: 511-514.

Barclay, H. J. 1992. Modelling the effects of population aggregation on the efficiency of insect pest control. Researches on Population Ecology 34: 131-141.

Barclay, H. J., and M. J. B. Vreysen. 2011. A dynamic population model for tsetse (Diptera: Glossinidae) area-wide integrated pest management. Population Ecology 53: 89-110. https://link.springer.com/article/10.1007/s10144-010-0224-7

Bartlett, A. C., and G. D. Butler, Jr. 1979. Pink bollworm: radiation sterility and computer simulation of population growth. Southwestern Entomologist 4: 216-223.

Baumhover, A. H. 2002. A personal account of developing the sterile insect technique to eradicate the screwworm from Curacao, Florida and the southeastern United States. Florida Entomologist 85: 666673. http://www.fcla.edu/FlaEnt/fe85p666.pdf

Bellini, R., A. Medici, A. Puggioli, F. Balestrino, and M. Carrieri. 2013. Pilot field trials with Aedes albopictus irradiated sterile males in Italian urban areas. Journal of Medical Entomology 50: $317-$ 325. https://doi.org/10.1603/ME12048

Benelli, G., K. M. Daane, A. Canale, C. Y. Niu, R. H. Messing, and R. I. Vargas. 2014. Sexual communication and related behaviours in Tephritidae: current knowledge and potential applications for Integrated Pest Management. Journal of Pest Science 87: 385-405. https://link.springer.com/article/10.1007/s10340-014-0577-3

Bloem, S., K. A. Bloem, and A. L. Knight. 1998. Assessing the quality of mass-reared codling moths (Lepidoptera: Tortricidae) by using field release-recapture tests. Journal of Economic Entomology 91: 1122-1130. https://doi.org/10.1093/jee/91.5.1122

Bloem, S., K. A. Bloem, and C. O. Calkins. 2000. Incorporation of diapause into codling moth mass rearing: production advantages and insect quality issues, pp. 329-335. In K. H. Tan (ed.), Proceedings: Area-Wide Control of Fruit Flies and Other Insect Pests. International Conference on Area-Wide Control of Insect Pests, and the $5^{\text {th }}$ International Symposium on Fruit Flies of Economic Importance, 28 May-5 June 1998, Penang, Malaysia. Penerbit Universiti Sains Malaysia, Pulau Pinang, Malaysia. http://www-naweb.iaea.org/nafa/ipc/public/Area-wide-control_230-350.pdf

Bloem, S., J. E. Carpenter, and S. Dorn. 2006. Mobility of mass-reared diapaused and nondiapaused Cydia pomonella (Lepidoptera: Tortricidae): Effect of different constant temperatures and lengths of cold storage. Journal of Economic Entomology 99: 707-713. https://doi.org/10.1603/0022-0493-99.3.707

Boppre, M. 1990. Lepidoptera and pyrrolizidine alkaloids. Exemplification of complexity in chemical ecology. Journal of Chemical Ecology 16: 165-185.

Borja, G. E. M. 2002. Biologia do Berne, comportamento, distribuicao, dinamica populacional, prejuizos e manejo integrado. A Hora Veterinaria 22(129): 41-44.

Bosa, C. F., L. Cruz-López, C. S. Zepeda-Cisneros, J. Valle-Mora, K. Guillén-Navarro, and P. Liedo. 2016. Sexual behavior and male volatile compounds in wild and mass-reared strains of the Mexican fruit fly Anastrepha ludens (Diptera: Tephritidae) held under different colony management regimes. Insect Science 23: 105-116. http://onlinelibrary.wiley.com/doi/10.1111/1744-7917.12180/abstract

Branson, T. F., J. J. Jackson, and G. R. Sutter. 1988. Improved method for rearing Diabrotica virgifera virgifera (Coleoptera: Chrysomelidae). Journal of Economic Entomology 81: 410-414.

Briceño, R. D., and W. G. Eberhard. 1998. Medfly courtship duration: a sexually selected reaction norm changed by crowding. Ethology, Ecology and Evolution 10: 369-382. 
Brower, J. H. 1975. Sperm precedence in the Indian meal moth, Plodia interpunctella. Annals of the Entomological Society of America 68: 78-80.

Brower, J. H. 1976. Recovery of fertility by irradiated males of the Indian meal moth. Journal of Economic Entomology 69: 273-276.

Brower, J. H., and E. W. Tilton. 1975. Potential for control of Cadra cautella (Walker) by release of fully or partially sterile males. International Journal of Applied Radiation and Isotopes 26: 720-725.

Carlson, D. A., D. R. Berkebile, S. R. Skoda, K. Mori, and S. Mihok. 2007. Candidate sex pheromones of the New World screwworm Cochliomyia hominivorax. Medical and Veterinary Entomology 21: 93-96. http://onlinelibrary.wiley.com/doi/10.1111/j.1365-2915.2006.00655.x/abstract

Carpenter, J. E., and H. R. Gross. 1989. Interaction of inherited sterility and diapause in the corn earworm (Lepidoptera: Noctuidae). Journal of Economic Entomology 82: 1354-1357.

Carpenter, J. E., and H. R. Gross. 1993. Suppression of feral Helicoverpa zea (Lepidoptera: Noctuidae) populations following the infusion of inherited sterility from released substerile males. Environmental Entomology 22: 1084-1091.

Carpenter, J. E., A. N. Sparks, and H. L. Cromroy. 1987. Corn earworm (Lepidoptera: Noctuidae): influence of irradiation and mating history on the mating propensity of females. Journal of Economic Entomology 80: 1233-1237.

Carpenter, J. E., Hidrayani, N. Nelly, and B. G. Mullinix. 1997. Effect of substerilizing doses of radiation on sperm precedence in fall armyworm (Lepidoptera: Noctuidae). Journal of Economic Entomology 90: 444-448.

Cayol, J. P. 2000. Changes in sexual behavior and life history traits of tephritid species caused by massrearing processes, pp. 843-860. In M. Aluja and A. L. Norrbom (eds.), Fruit flies (Tephritidae): phylogeny and evolution of behavior. CRC Press LLC, Boca Raton, FL, USA.

Cayol, J. P., and M. Zarai. 1999. Field releases of two genetic sexing strains of the Mediterranean fruit fly (Ceratitis capitata Wied.) in two isolated oases of Tozeur governorate, Tunisia. Journal of Applied Entomology 123: 613-619.

Cayol, J. P., P. Coronado, and M. Taher. 2002. Sexual compatibility in medfly (Diptera: Tephritidae) from different origins. Florida Entomologist 85: 51-57. http://www.fcla.edu/FlaEnt/fe85p51.pdf

Chang, C. L., R. Kurashima, and C. Albrecht. 2000. Effect of limiting concentrations of growth factors in mass rearing diets for Ceratitis capitata larvae (Diptera: Tephritidae). Annals of the Entomological Society of America 93: 898-903. https://doi.org/10.1603/0013-8746(2000)093[0898:EOLCOG]2.0.CO;2

Charlton, R. E., and R. T. Cardé. 1990. Factors mediating copulatory behavior and close-range mate recognition in the male gypsy moth, Lymantria dispar (L.). Canadian Journal of Zoology 68: 19952004. https://doi.org/10.1139/z90-281

Cirio, U. 1974. Ecological bases for a programme of control against Ceratitis capitata Wied. on the Island of Procida. Redia 55: 189-201.

Cirio, U., I. D. d. Murtas, S. Gozzo, D. Enkerlin, and I. D. De Murtas. 1972. Preliminary ecological observations of Ceratitis capitata Wied. on the island of Procida with an attempt to control the species using the sterile-male technique. Bollettino del Laboratorio di Entomologia Agraria 'Filippo Silvestri' Portici 30: 175-188.

Conner, J. K. 1995. Extreme variability in sperm precedence in the fungus beetle, Bolitotherus cornutus (Coleoptera: Tenebrionidae). Ethology, Ecology and Evolution 7: 277-280.

Da Silva, C. S. B., and J. R. P. Parra. 2013. New method for rearing Spodoptera frugiperda in laboratory shows that larval cannibalism is not obligatory. Revista Brasileira de Entomologia 57: 347-349. http://dx.doi.org/10.1590/S0085-56262013005000029

Damiens, D., M. Q. Benedict, M. Wille, and J. R. L. Gilles. 2012. An inexpensive and effective larval diet for Anopheles arabiensis (Diptera: Culicidae): eat like a horse, a bird, or a fish? Journal of Medical Entomology 49: 1001-1011. https://doi.org/10.1603/ME11289

Dominiak, B. C., and H. I. Nicol. 2010. Field performance of Lynfield and McPhail traps for monitoring male and female sterile Bactrocera tryoni (Froggatt) and wild Dacus newmani (Perkins). Pest Management Science 66: 741-744. http://onlinelibrary.wiley.com/doi/10.1002/ps.1936/abstract

Dubois, T., A. E. Hajek, and S. Smith. 2002. Methods for rearing the Asian longhorned beetle (Coleoptera: Cerambycidae) on artificial diet. Annals of the Entomological Society of America 95: 223-230. https://doi.org/10.1603/0013-8746(2002)095[0223:MFRTAL]2.0.CO;2

Eberhard, W. G. 1996. Female control: sexual selection by cryptic female choice. Princeton University Press, Princeton, NJ, USA. 
Economopoulos, A. P. 1977. Gamma-ray sterilization of Dacus oleae (Gmelin). Effect of nitrogen on the competitiveness of irradiated males. Zeitschrift für Angewandte Entomologie 83: 86-95.

Economopoulos, A. P., A. A. Al Taweel, and N. D. Bruzzone. 1990. Larval diet with a starter phase for mass-rearing Ceratitis capitata: substitution and refinement in the use of yeasts and sugars. Entomologia Experimentalis et Applicata 55: 239-246.

Edman, J. D., and K. R. Simmons. 1985. Simuliids (mainly Simulium decorum Walker), pp. 145-152. In P. Singh and R. F. Moore (eds.), Handbook of insect rearing. Elsevier, Amsterdam, The Netherlands.

El Agoze, M., M. Poirie, and G. Periquet. 1995. Precedence of the first male sperm in successive matings in the Hymenoptera Diadromus pulchellus. Entomologia Experimentalis et Applicata 75 : $251-255$.

Etman, A. A. M., and G. H. S. Hooper. 1979. Sperm precedence of the last mating in Spodoptera litura. Annals of the Entomological Society of America 72: 119-120.

(FAO) Food and Agriculture Organization of the United Nations. 1992. The New World screwworm eradication programme: North Africa 1988-1992. FAO, Rome, Italy. https://www.iaea.org/sites/default/files/18/03/ipc-screwworm-libya-1992-full.pdf

(FAO/IAEA/USDA) Food and Agriculture Organization of the United Nations/International Atomic Energy Agency/United States Department of Agriculture. 2019. Product quality control for sterile mass-reared and released tephritid fruit flies. Version 7.0. IAEA, Vienna, Austria. 148 pp. https://www.iaea.org/sites/default/files/qcv7.pdf

Fay, H. A. C., and A. Meats. 1987. The sterile insect release method and the importance of thermal conditioning before release: field-cage experiments with Dacus tryoni in spring weather. Australian Journal of Zoology 35: 197-204.

Fontenot, E. A., F. H. Arthur, and K. L. Hartzer. 2015. Effect of diet and refugia on development of Dermestes maculatus DeGeer reared in a laboratory. Journal of Pest Science 88: 113-119. https://link.springer.com/article/10.1007/s10340-014-0562-x

Gavriel, S., Y. Gazit, A. Leach, J. Mumford, and B. Yuval. 2012. Spatial patterns of sterile Mediterranean fruit fly dispersal. Entomologia Experimentalis et Applicata 142: 17-26. http://onlinelibrary.wiley.com/doi/10.1111/j.1570-7458.2011.01197.x/abstract

González-López, G. I., D. Rao, F. Díaz-Fleischer, D. Orozco-Dávila, and D. Pérez-Staples. 2016. Antipredator behavior of the new mass-reared unisexual strain of the Mexican fruit fly. Bulletin of Entomological Research 106: 314-321. DOI: 10.1017/S0007485315000966 https://pubag.nal.usda.gov/catalog/5217141

Guillot, F. S., H. E. Brown, and A. B. Broce. 1978. Behavior of sexually active male screwworm flies. Annals of the Entomological Society of America 71: 199-201.

Hammack, L. 1987. Chemical basis for asymmetric mating isolation between strains of screwworm fly, Cochliomyia hominivorax. Journal of Chemical Ecology 13: 1419-1430.

Hammack, L. 1992. Intra- and interspecific sex pheromone responses of screwworm and secondary screwworm flies. Journal of Chemical Ecology 18: 1327-1336.

Haynes, J. W., and E. B. Mitchell. 1977. Fractionated irradiation of boll weevils during pupal development: effect of sperm depletion and transfer as measured by female responsiveness. Journal of Economic Entomology 70: 411-412.

Heath, R. R., N. D. Epsky, B. D. Dueben, A. Guzman, and L. E. Andrade. 1994. Gamma radiation effect on production of four pheromonal components of male Mediterranean fruit flies (Diptera: Tephritidae). Journal of Economic Entomology 87: 904-909.

Hendrichs, J., and M. A. Hendrichs. 1990. Mediterranean fruit fly (Diptera: Tephritidae) in nature: location and diel pattern of feeding and other activities on fruiting and non-fruiting hosts and nonhosts. Annals of the Entomological Society of America 83: 632-641.

Hendrichs, J., A. S. Robinson, J. P. Cayol, and W. Enkerlin. 2002. Medfly areawide sterile insect technique programmes for prevention, suppression, or eradication: the importance of mating behavior studies. Florida Entomologist 85: 1-13. http://www.fcla.edu/FlaEnt/fe85p1.pdf

Hendrichs, M. A., and J. Hendrichs. 1998. Perfumed to be killed: interception of Mediterranean fruit fly Ceratitis capitata Wied. (Diptera: Tephritidae) sexual signalling by foraging wasp predators. Annals of the Entomological Society of America 91: 228-234.

Hendrichs, M. A., V. Wornoayporn, B. Katsoyannos, and J. Hendrichs. 2007. Quality control method to measure predator evasion in wild and mass-reared Mediterranean fruit flies (Diptera: Tephritidae). Fl. Entomologist 90(1): 64-70. https://journals.flvc.org/flaent/article/view/75615/73273 
Hendricks, D. E., H. M. Graham, and J. R. Raulston. 1973. Dispersal of sterile tobacco budworms from release points in northeastern Mexico and southern Texas. Environmental Entomology 2: 10851088.

Hibino, Y., and O. Iwahashi. 1991. Appearance of wild females unreceptive to sterilized males on Okinawa Is. in the eradication programme of the melon fly, Dacus cucurbitae Coquillett (Diptera: Tephritidae). Applied Entomology and Zoology 26: 265-270.

(ISO/ASTM) American Society for Testing and Materials. 2013. Guide for dosimetry for sterile insects release programs. ISO/ASTM 51940:2013(E). ASTM, West Conshohocken, PA, USA. https://www.iso.org/standard/61087.html

Itô, Y., and J. Koyama. 1982. Eradication of the melon fly: role of population ecology in the successful implementation of the sterile insect release method. Protection Ecology 4: 1-28.

Iwahashi, O. 1976. Suppression of the melon fly, Dacus cucurbitae Coquillett (Diptera: Tephritidae), on Kudaka Is. with sterile insect releases. Applied Entomology and Zoology 11: 100-110.

Jang, E. B., D. M. Light, R. A. Flath, J. T. Nagata, and T. R. Mon. 1989. Electroantennogram responses of the Mediterranean fruit fly, Ceratitis capitata to identified volatile constituents from calling males. Entomologia Experimentalis et Applicata 50: 7-19.

Jang, E. B., D. O. McInnis, D. R. Lance, and L. A. Carvalho. 1998. Mating-induced changes in olfactory-mediated behavior of laboratory-reared normal, sterile, and wild female Mediterranean fruit flies (Diptera: Tephritidae) mated to conspecific males. Annals of the Entomological Society of America 91: 139-144. https://doi.org/10.1093/aesa/91.1.139

Jones, C. J., S. A. Isard, and M. R. Cortinas. 1999. Dispersal of synanthropic Diptera: lessons from the past and technology for the future. Annals of the Entomological Society of America 92: 829-839. https://doi.org/10.1093/aesa/92.6.829

Keena, M. A., T. M. O'Dell, and J. A. Tanner. 1998. Environmentally-based maternal effects are primary factor in determining the developmental response of gypsy moth (Lepidoptera: Lymantriidae) to dietary iron deficiency. Annals of the Entomological Society of America 91: 710718. https://doi.org/10.1093/aesa/91.5.710

Klein, M. G., and P. G. Allsopp. 1994. Artificial diets for third instar Japanese beetle (Coleoptera: Scarabaeidae). Journal of Entomological Science 29: 585-589.

Knipling, E. F. 1955. Possibilities in insect control or eradication through the use of sexually sterile males. Journal of Economic Entomology 48: 459-462. https://doi.org/10.1093/jee/48.4.459

Knipling, E. F. 1968. The potential role of sterility for pest control, pp. 7-40. In G. C. LaBrecque and C. N. Smith (eds.), Principles of insect chemosterilization. Appleton-Century-Crofts, New York, NY, USA.

Knipling, E. F. 1979. The basic principles of insect population suppression and management. Agriculture Handbook, Number 512. Science and Education Administration, United States Department of Agriculture, Washington, D.C., USA.

Knipling, E. F. 1998. Role of parasitoid augmentation and sterile insect techniques in areawide management of agricultural insect pests. Journal of Agricultural Entomology 15: 273-301.

Kohama, T., and H. Kuba. 1996. Movement of sterile melon flies in Okinawa, Japan, pp. 415-423. In B. A. McPheron and G. J. Steck (eds.), Fruit fly pests: a world assessment of their biology and management. St. Lucie Press, Delray Beach, FL, USA.

Koyama, J., and K. Tanaka. 1984. Invasion of Kume Is. by the melon fly, Dacus cucurbitae Coquillett, after eradication of the insect and control measures. Japanese Journal of Applied Entomology and Zoology 28: 63-67.

Kraaijeveld, K., B. I. Katsoyannos, M. Stavrinides, N. A. Kouloussis, and T. Chapman. 2005. Remating in wild females of the Mediterranean fruit fly, Ceratitis capitata. Animal Behaviour 69: 771-776. https://doi.org/10.1016/j.anbehav.2004.06.015

Krafsur, E. S. 1998. Sterile insect technique for suppressing and eradicating insect population: 55 years and counting. Journal of Agricultural Entomology 15: 303-317.

Kuba, H., and Y. Itô. 1993. Remating inhibition in the melon fly, Bactrocera (= Dacus) cucurbitae (Diptera: Tephritidae): copulation with spermless males inhibits female remating. Journal of Ethology 11: 23-28.

Kuba, H., T. Kohama, H. Kakinohana, M. Yamagishi, K. Kinjo, Y. Sokei, T. Nakasone, and Y. Nakamoto. 1996. The successful eradication programmes of the melon fly in Okinawa, pp. 543550. In B. A. McPheron and G. J. Steck (eds.), Fruit fly pests: a world assessment of their biology and management. St. Lucie Press, Delray Beach, FL, USA. 
LaBrecque, G. C., and C. N. Smith. 1968. Principles of insect chemosterilization. Appleton-CenturyCrofts, New York, NY, USA. 354 p.

LaChance, L. E. 1975. Induced sterility in irradiated Diptera and Lepidoptera: sperm transfer and dominant lethal mutations, pp. 401-410. In Proceedings, Symposium: Sterility Principle for Insect Control 1974. International Atomic Energy Agency and Food and Agriculture Organization of the United Nations, 22-26 July 1974, Innsbruck, Austria. STI/PUB/377. IAEA, Vienna, Austria. https://www.iaea.org/sites/default/files/18/03/ipc-sterility-insects-1975_1-cvr_full.pdf

LaChance, L. E., D. R. Birkenmeyer, and R. L. Ruud. 1979. Inherited F1 sterility in the male pink bollworm: reduction of eupyrene sperm bundles in the testis and duplex. Annals of the Entomological Society of America 72: 343-347.

LaMunyon, C. W. 2001. Determinants of sperm precedence in a noctuid moth Heliothis virescens: a role for male age. Ecological Entomology 26: 388-394. http://onlinelibrary.wiley.com/doi/10.1046/j.1365-2311.2001.00336.x/full

LaMunyon, C. W., and T. S. Huffman. 2001. Determinants of sperm transfer by males of the noctuid moth Heliothis virescens. Journal of Insect Behavior 14: 187-199. https://link.springer.com/article/10.1023/A\%3A1007885611145

Lance, D. R. 2014. Integrating tephritid trapping into phytosanitary programs, pp. 559-588. In T. E. Shelly, N. Epsky, E. B. Jang, J. Reyes-Flores and R. I. Vargas (eds.), Trapping and the detection, control, and regulation of tephritid fruit flies: lures, area-wide programs, and trade implications. Springer, Dordrecht, The Netherlands.

Lance, D. R., T. M. O'Dell, V. C. Mastro, and C. P. Schwalbe. 1988. Temperature-mediated programming of activity rhythms in male gypsy moths (Lepidoptera: Lymantriidae): implications for the sterile male technique. Environmental Entomology 17: 649-653.

Lance, D. R., D. O. McInnis, P. Rendón, and C. G. Jackson. 2000. Courtship among sterile and wild Ceratitis capitata (Diptera: Tephritidae) in field cages in Hawaii and Guatemala. Annals of the Entomological Society of America 93: 1179-1185. https://doi.org/10.1603/0013-8746(2000)093[1179:CASAWC]2.0.CO;2

Lance, D. R., W. M. Woods, and M. Stefan. 2014. Invasive insects in plant biosecurity: Case study Mediterranean fruit fly, pp. 547-592. In G. Gordh and S. McKirdy (eds.), The handbook of plant biosecurity. Springer, Dordrecht, The Netherlands.

Leftwich, P. T., M. Koukidou, P. Rempoulakis, H. F. Gong, A. Zacharopoulou, G. L. Fu, T. Chapman, A. Economopoulos, J. Vontas, and L. Alphey. 2014. Genetic elimination of field-cage populations of Mediterranean fruit flies. Proceedings of the Royal Society B. Biological Sciences 281(1792): 20141372. http://dx.doi.org/10.1098/rspb.2014.1372

Leopold, R. A. 2007. Colony maintenance and mass-rearing: using cold storage technology for extending the shelf-life of insects, pp. 149-162. In M. J. B. Vreysen, A. S. Robinson and J. Hendrichs (eds.), Area-wide control of insect pests: from research to field implementation. Springer, Dordrecht, The Netherlands.

http://www-naweb.iaea.org/nafa/ipc/public/Area-Wide-Control-Insect-Pests-book.pdf

Leppla, N. C., M. D. Huettel, D. L. Chambers, T. R. Ashley, D. H. Miyashita, T. T. Y. Wong, and E. J. Harris. 1983. Strategies for colonization and maintenance of the Mediterranean fruit fly. Entomologia Experimentalis et Applicata 33: 89-96.

Lindquist, A. W. 1969. Biological information needed in the sterile-male method of insect control, pp. 33-37. In Proceedings, Panel: Sterile-Male Technique for Eradication or Control of Harmful Insects. Joint FAO/IAEA Division of Atomic Energy in Food and Agriculture, 27-31 May 1968, Vienna, Austria. STI/PUB/224. IAEA, Vienna, Austria. https://www.iaea.org/sites/default/files/el_harmful_insects.pdf

Lindquist, D. A., B. A. Butt, and I. Moore. 1974. Ecological requirements of the sterile male technique, pp. 249-262. In Proceedings: FAO Conference on Ecology in Relation to Plant Pest Control, 11-15 December 1972, Rome, Italy. FAO, Rome, Italy.

Liquido, N., G. McQuate, and K. Suiter. 2015. Medhost: an encyclopedic bibliography of the host plants of the Mediterranean fruit fly, Ceratitis capitata (Wiedemann). Version 3.0. USDA-APHISPPQ-S\&T, Center for Plant Health Science and Technology, Raleigh, NC, USA.

https://medhost.cphst.org

Mangan, R. L. 1991. Analysis of genetic control of mating behavior in screwworm (Diptera: Calliphoridae) males through diallel crosses and artificial selection. Theoretical and Applied Genetics 81: 429-436. 
Mastro, V. C. 1978. Development and assessment of techniques for comparing the competitiveness of populations of male gypsy moths, pp. 139-145. Otis Methods Development Center Progress Report. USDA/APHIS, Otis ANG Base, MA, USA.

Mastro, V. C., and C. P. Schwalbe. 1988. Status and potential of $F_{1}$ sterility for control of noxious Lepidoptera, pp. 15-40. In Proceedings, Symposium: Modern Insect Control: Nuclear Techniques and Biotechnology. International Atomic Energy Agency and Food and Agriculture Organization of the United Nations, 16-20 November 1987, Vienna, Austria. STI/PUB/763. IAEA, Vienna, Austria. https:/www.iaea.org/sites/default/files/ipc-modern-insect-control.pdf

Mattanovich, J., M. Ehrenhöfer, C. Vavra, and E. Führer. 1999. Further development of a semiartificial diet for Ips typographus L. Anzeiger für Schädlingskunde 72: 49-51.

Matthews, R. W., and J. R. Matthews. 2009. Insect behavior. 2nd edn. Springer, Dordrecht, The Netherlands. 507 p.

McGraw, L. 2001. Squeezing out screwworm. Agricultural Research 49: 18-21. https://agresearchmag.ars.usda.gov/2001/apr/worm

McInnis, D. O., and R. T. Cunningham. 1986. Minimum sampling of trap catches in sterile insect release programmes. Journal of Economic Entomology 79: 879-881.

McInnis, D. O., J. W. Mackley, and R. D. Peterson, II. 1985. Native fly dispersal in the field: evaluation of a prospective factory strain of the screwworm, Cochliomyia hominivorax (Coquerel) (Diptera: Calliphoridae). Environmental Entomology 14: 101-105.

McInnis, D. O., S. Tam, C. Grace, and D. Miyashita. 1994. Population suppression and sterility rates induced by variable sex ratio, sterile insect releases of Ceratitis capitata (Diptera: Tephritidae) in Hawaii. Annals of the Entomological Society of America 87: 231-240.

McInnis, D. O., D. R. Lance, and C. G. Jackson. 1996. Behavioral resistance to the sterile insect technique by Mediterranean fruit fly (Diptera: Tephritidae) in Hawaii. Annals of the Entomological Society of America 89: 739-744.

McInnis, D. O., T. E. Shelly, and J. Komatsu. 2002. Improving male mating competitiveness and survival in the field for medfly, Ceratitis capitata (Diptera: Tephritidae) SIT programs. Genetica 116: 117-124. https://link.springer.com/article/10.1023/A:1020919927542

McInnis, D., R. Kurashima, T. Shelly, J. Komatsu, J. Edu, and E. Pahio. 2011. Prerelease exposure of methyl eugenol increases the mating competitiveness of sterile males of the oriental fruit fly (Diptera: Tephritidae) in a Hawaiian orchard. Journal of Economic Entomology 104: 1969-1978. https://doi.org/10.1603/EC11134

McInnis, D. O., B. J. Paranhos, and T. E. Shelly. 2013. Survival of sterile male Mediterranean fruit flies in large field cages after release at different ages. Journal of Applied Entomology 137 (Suppl. 1): 43-48. http://onlinelibrary.wiley.com/doi/10.1111/j.1439-0418.2010.01567.x/full

McKibben, G. H., E. J. Villavaso, W. L. McGovern, and B. Grefenstette. 2001. United States Department of Agriculture - research support, methods development and programme implementation. In W. A. Dickerson, A. L. Brashear, J. T. Brumley, F. L. Carter, W. J. Grefenstette and F. A. Harris (eds.), Boll weevil eradication in the United States through 1999. Cotton Foundation Publisher, Memphis, TN, USA.

Meats, A. 1998. A quality assurance measure for field survival rates of released sterile flies based on recapture rates. General and Applied Entomology 28: 39-46.

Meats, A. 2007. Dispersion of fruit flies (Diptera: Tephritidae) at high and low densities and consequences of mismatching dispersions of wild and sterile flies. Florida Entomologist 90: 136146. https://doi.org/10.1653/0015-4040(2007)90[136:DOFFDT]2.0.CO;2

Meats, A., H. M. Holmes, and G. L. Kelly. 2004. Laboratory adaptation of Bactrocera tryoni (Diptera: Tephritidae) decreases mating age and increases protein consumption and number of eggs produced per milligram of protein. Bulletin of Entomological Research 94: 517-524. https://doi.org/10.1079/BER2004332

Miyatake, T., and T. Shimizu. 1999. Genetic correlations between life-history and behavioural traits can cause reproductive isolation. Evolution 53: 201-208.

Morrison, N. I., G. S. Simmons, G. Fu, S. O'Connell, A. S. Walker, T. Dafa'alla, M. Walters, J. Claus, G. L. Tang, L. Jin, T. Marubbi, M. J. Epton, C. L. Harris, R. T. Staten, E. Miller, T. A. Miller, and L. Alphey. 2012. Engineered repressible lethality for controlling the pink bollworm, a lepidopteran pest of cotton. PLOS ONE 7(12): e50922. https://doi.org/10.1371/journal.pone.0050922

Moya, P., S. Flores, I. Ayala, J. Sanchis, P. Montoya, and J. Primo. 2010. Evaluation of lufenuron as a chemosterilant against fruit flies of the genus Anastrepha (Diptera: Tephritidae). Pest Management Science 66: 657-663. http://onlinelibrary.wiley.com/doi/10.1002/ps.1925/abstract 
Nakamori, H., and M. Shiga. 1993. Characteristics of hot spots of melon fly, Bactrocera (Dacus) cucurbitae Coquillett (Diptera: Tephritidae) in sterile fly release areas on Okinawa Island. Japanese Journal of Applied Entomology and Zoology 37: 123-128.

Nishida, R., T. E. Shelly, and K. Y. Kaneshiro. 1997. Acquisition of female-attracting fragrance by males of Oriental fruit fly from a Hawaiian lei flower, Fagraea berteriana. Journal of Chemical Ecology 23: 2275-2285.

North, D. T., J. W. Snow, D. Haile, and F. I. Proshold. 1975. Corn earworms: quality of sperm in sterile males released for population suppression on St. Croix Island. Journal of Economic Entomology 68: 595-598.

Opiyo, E., D. Luger, and A. S. Robinson. 2000. New systems for the large-scale production of male tsetse flies (Diptera: Glossinidae), pp. 337-344. In K. H. Tan (ed.), Proceedings: Area-Wide Control of Fruit Flies and Other Insect Pests. International Conference on Area-Wide Control of Insect Pests, and the $5^{\text {th }}$ International Symposium on Fruit Flies of Economic Importance, 28 May-5 June 1998, Penang, Malaysia. Penerbit Universiti Sains Malaysia, Pulau Pinang, Malaysia. http://www-naweb.iaea.org/nafa/ipc/public/Area-wide-control_230-350.pdf

Orozco-Dávila, D., T. Artiaga-López, M. D. R. Hernández, J. Domínguez, and E. Hernández. 2014. Anastrepha obliqua (Diptera: Tephritidae) mass-rearing: effect of relaxed colony management. International Journal of Tropical Insect Science 34(S1): S19-S27. https://doi.org/10.1017/S1742758414000058

Ozaki, E. T., and R. M. Kobayashi. 1981. Effects of pupal handling during laboratory rearing on adult eclosion and flight capability in three tephritid species. Journal of Economic Entomology 74: 520525.

Patterson, R. S., and J. A. Miller. 1982. The sterile insect technique in integrated pest management programmes for the control of stable flies and horn flies, pp. 111-122. In Proceedings, Symposium: Sterile Insect Technique and Radiation in Insect Control. Food and Agriculture Organization of the United Nations, and the International Atomic Energy Agency, 29 June-3 July 1981, Neuherberg, Germany. STI/PUB/595. IAEA, Vienna, Austria.

https://www.iaea.org/sites/default/files/sit-radiation-proceedings-1982.pdf

Penrose, D. 1996. California's 1993/1994 Mediterranean fruit fly eradication programme, pp. 551-554. In B. A. McPheron and G. J. Steck (eds.), Fruit fly pests: a world assessment of their biology and management. St. Lucie Press, Delray Beach, FL, USA.

Pereira, R., B. Yuval, P. Liedo, P. E. A. Teal, T. E. Shelly, D. O. McInnis, and J. Hendrichs. 2013. Improving sterile male performance in support of programmes integrating the sterile insect technique against fruit flies. Journal of Applied Entomology 137 (S1): 178-190. http://onlinelibrary.wiley.com/doi/10.1111/j.1439-0418.2011.01664.x/abstract

Pomonis, J. G., and J. W. Mackley. 1985. Gas chromatographic composition profiles of surface lipid extracts from screwworm compared by age, sex, colonisation and geography. Southwestern Entomologist 10: 65-76.

Prokopy, R. J., and J. Hendrichs. 1979. Mating behavior of Ceratitis capitata on a field-caged host tree. Annals of the Entomological Society of America 72: 642-648.

Proshold, F. I., J. R. Raulston, D. F. Martin, and M. L. Laster. 1983. Release of backcross insects on St. Croix to suppress the tobacco budworm (Lepidoptera: Noctuidae): behavior and interaction with native insects. Journal of Economic Entomology 76: 626-631.

Proshold, F. I., V. C. Mastro, and G. L. Bernon. 1993. Sperm transfer by gypsy moths (Lepidoptera: Lymantriidae) from irradiated males: implication for control by inherited sterility. Journal of Economic Entomology 86: 1104-1108.

Prout, T. 1978. The joint effects of the release of sterile males and immigration of fertilized females on a density regulated population. Theoretical Population Biology 13: 40-71.

Quintero-Fong, L., J. Toledo, L. Ruiz, P. Rendón, D. Orozco-Dávila, L. Cruz, and P. Liedo. 2016. Selection by mating competitiveness improves the performance of Anastrepha ludens males of the genetic sexing strain Tapachula-7. Bulletin of Entomological Research 106: 624-632. https://doi.org/10.1017/S0007485316000316

Rendón, P., D. McInnis, D. Lance, and J. Stewart. 2004. Medfly (Diptera: Tephritidae) genetic sexing: large-scale field comparison of males-only and bisexual sterile fly releases in Guatemala. Journal of Economic Entomology 97: 1547-1553. https://doi.org/10.1603/0022-0493-97.5.1547

Ringo, J. 1996. Sexual receptivity in insects. Annual Review of Entomology 41: 473-494. https://doi.org/10.1146/annurev.en.41.010196.002353 
Robacker, D. C., R. L. Mangan, D. S. Moreno, and A. M. T. Moreno. 1991. Mating behavior and male mating success in wild Anastrepha ludens (Diptera: Tephritidae) on a field-caged host tree. Journal of Insect Behavior 4: 471-487.

Rossler, Y., E. Ravins, P. J. Gomes, J. Katan, N. Aharonson, E. Cohen, B. Rubin, and G. A. Matthews. 2000. Sterile insect technique (SIT) in the near east - a transboundary bridge for development and peace. Crop Protection 19: 733-738. https://doi.org/10.1016/S0261-2194(00)00097-1

Saul, S. H., and S. D. McCombs. 1993. Dynamics of sperm use in the Mediterranean fruit fly (Diptera: Tephritidae): reproductive fitness of multiple-mated females and sequentially mated males. Annals of the Entomological Society of America 86: 198-202.

Sarvary, M. A., S. D. Hight, J. E. Carpenter, S. Bloem, K. A. Bloem, and S. Dorn. 2008. Identification of factors influencing flight performance of field-collected and laboratory-reared, overwintered, and nonoverwintered cactus moths fed with field-collected host plants. Environmental Entomology 37: 1291-1299. https://doi.org/10.1093/ee/37.5.1291

Sawyer, A. J., Z. Feng, C. W. Hoy, R. L. James, S. E. Naranjo, S. E. Webb, and C. Welty. 1987. Instructional simulation: sterile insect release method with spatial and random effects. Bulletin of the Entomological Society of America 33: 182-190.

Scolari, F., B. Yuval, L. M. Gomulski, M. F. Schetelig, P. Gabrieli, F. Bassetti, E. A. Wimmer, A. R. Malacrida, and G. Gasperi. 2014. Polyandry in the medfly - shifts in paternity mediated by sperm stratification and mixing. BMC Genetics 15(S2): S10. http://www.biomedcentral.com/1471-2156/15/S2/S10

Seawright, J. A. 1988. Genetic methods for control of mosquitoes and biting flies, pp. 179-191. In Proceedings, Symposium: Modern Insect Control: Nuclear Techniques and Biotechnology. International Atomic Energy Agency and Food and Agriculture Organization of the United Nations, 16-20 November 1987, Vienna, Austria. STI/PUB/763. IAEA, Vienna, Austria. https://www.iaea.org/sites/default/files/ipc-modern-insect-control.pdf

Shelly, T. E. 2012. Mate choice by wild and mass-reared females of the Mediterranean fruit fly. Journal of Applied Entomology 136: 238-240. http://onlinelibrary.wiley.com/doi/10.1111/j.1439-0418.2011.01627.x/full

Shelly, T. E., and D. O. McInnis. 2001. Exposure to ginger root oil enhances mating success of irradiated, mass-reared males of Mediterranean fruit fly (Diptera: Tephritidae). Journal of Economic Entomology 94: 1413-1418. https://doi.org/10.1603/0022-0493-94.6.1413

Shelly, T., and D. McInnis. 2016. Sterile insect technique and control of tephritid fruit flies: do species with complex courtship require higher overflooding ratios? Annals of the Entomological Society of America 109: 1-11. https://doi.org/10.1093/aesa/sav101

Shelly, T. E., J. Edu, and D. McInnis. 2010. Pre-release consumption of methyl eugenol increases the mating competitiveness of sterile males of the oriental fruit fly, Bactrocera dorsalis, in large field enclosures. Journal of Insect Science 10(8): 1-16. http://www.bioone.org/doi/full/10.1673/031.010.0801

Shiga, M. 1986. Analysis of spatial distribution in fruit fly eradication, pp. 387-398. In M. Mangel, J. R. Carey and R. E. Plant (eds.), Proceedings: Pest Control: Operations and Systems Analysis in Fruit Fly Management. NATO Advanced Workshop, 5-9 August 1985, Bad Windsheim, Germany. Springer-Verlag, Berlin, Germany.

Spates, G. E., and B. G. Hightower. 1970. Variations in size and reproductive capacity of wild-type and laboratory-adapted populations of the screwworm fly. Journal of Economic Entomology 83: 1381-1385.

Stadelbacher, E. A., and D. F. Martin. 1981. Fall diapause and spring emergence of Heliothis virescens, H. subflexa, and backcrosses of their hybrid. Environmental Entomology 10: 139-142.

Staten, R. T., and M. L. Walters. 2021. Technology used by field managers for pink bollworm eradication with its successful outcome in the United States and Mexico, pp. 51-92. In J. Hendrichs, R. Pereira and M. J. B. Vreysen (eds.), Area-wide integrated pest management. Development and field application. CRC Press, Boca Raton, FL, USA.

Staten, R., M. Walters, R. Roberson, S. Birdsall, P. Dugger, and D. Richter. 1999. Area-wide management/maximum suppression of pink bollworm [Pectinophora gossypiella] in southern California, pp. 985-988. In Proceedings: Beltwide Cotton Conferences. National Cotton Council, Memphis, TN, USA.

Steffan, A. W., and W. J. Kloft. 1973. The possibilities of using the sterile male technique for aphid control - a theoretical discussion, pp. 129-136. In Proceedings, Panel: Computer Models and 
Application of the Sterile-Male Technique. Joint FAO/IAEA Division of Atomic Energy in Food and Agriculture, 13-17 December 1971, Vienna, Austria. STI/PUB/340. IAEA, Vienna, Austria.

https://www.iaea.org/sites/default/files/el_computer_models.pdf

Suenaga, H., A. Tanaka, H. Kamiwada, T. Kamikado, and N. Chishaki. 2000. Long-term changes in age-specific egg production of two Bactrocera cucurbitae (Diptera: Tephritidae) strains mass-reared under different selection regimes, with different egg collection methods. Applied Entomology and Zoology 35: 13-20. https://doi.org/10.1303/aez.2000.13

Sutter, G. R., D. R. Lance, L. J. Meinke, J. E. Frana, R. L. Metcalf, E. Levine, and J. M. Gaggero. 1998. Managing corn rootworms with a granular semiochemical-based bait: a 1990 multistate evaluation. USDA, Washington, DC, USA.

Templeton, A. R. 1978. Genetics of colonization and establishment of exotic species, pp. 41-49. In M. A. Hoy and J. J. McKelvey, Jr. (eds.), Genetics in relation to insect management. Rockefeller Foundation Working Papers, Bellagio, Italy. The Rockefeller Foundation, New York, NY, USA.

Thailayil, J., K. Magnusson, H. Charles, J. Godfray, A. Crisanti, and F. Catteruccia. 2011. Spermless males elicit large-scale female responses to mating in the malaria mosquito Anopheles gambiae. Proceedings of the National Academy of Sciences of the United States of America 108(33): 13677-13681. DOI: 10.1073/pnas.1104738108 http://www.pnas.org/content/108/33/13677.abstract

Thomas, D. B., and J. Loera Gallardo. 1998. Dispersal and longevity of mass-released, sterilized Mexican fruit flies (Diptera: Tephritidae). Environmental Entomology 27: 1045-1052.

Thomas, D. B., and R. L. Mangan. 2005. Nontarget impact of spinosad GF-120 bait sprays for control of the Mexican fruit fly (Diptera: Tephritidae) in Texas citrus. Journal of Economic Entomology 98: 1950-1956. https://doi.org/10.1603/0022-0493-98.6.1950

Vaníčková, L., R. R. do Nascimento, M. Hoskovec, Z. Ježková, R. Břízová, A. Tomčala, and B. Kalinová. 2012. Are the wild and laboratory insect populations different in semiochemical emission? The case of the medfly sex pheromone. Journal of Agricultural and Food Chemistry 60(29): 7168-7176. http://pubs.acs.org/doi/abs/10.1021/jf301474d

Vargas, R. I., W. A. Walsh, C. L. Hsu, J. Spencer, B. Mackey, and L. Whitehand. 1994. Effects of sterile Mediterranean fruit fly (Diptera: Tephritidae) releases on the target species, a non-target tephritid, and a braconid parasitoid (Hymenoptera: Braconidae) in commercial coffee fields. Journal of Economic Entomology 87: 653-660.

Vargas, R. I., L. Whitehand, W. A. Walsh, J. P. Spencer, C. Hsu, and C. L. Hsu. 1995. Aerial releases of sterile Mediterranean fruit fly (Diptera: Tephritidae) by helicopter: dispersal, recovery, and population suppression. Journal of Economic Entomology 88: 1279-1287.

Villavaso, E. J., W. L. McGovern, T. L. Wagner, and J. L. Willers. 1998. Components of competitiveness in sterile male boll weevils (Coleoptera: Curculionidae). Journal of Economic Entomology 91: 631-636. https://doi.org/10.1093/jee/91.3.631

Waage, J. K. 1979. Dual function of the damselfly Calopteryx maculata penis: sperm removal and transfer. Science 203: 916-918.

Williamson, D. L., S. Mitchell, and S. T. Seo. 1985. Gamma irradiation of the Mediterranean fruit fly (Diptera: Tephritidae): effects of puparial age under induced hypoxia on female sterility. Annals of the Entomological Society of America 78: 101-106.

Wong, T. T. Y., J. I. Nishimoto, and N. Mochizuki. 1983. Infestation patterns of Mediterranean fruit fly and the Oriental fruit fly (Diptera: Tephritidae) in the Kula area of Maui, Hawaii. Environmental Entomology 12: 1031-1039.

Wong, T. T. Y., R. M. Kobayashi, and D. O. McInnis. 1986. Mediterranean fruit fly (Diptera: Tephritidae): methods of assessing the effectiveness of sterile insect releases. Journal of Economic Entomology 79: 1501-1506.

Yuval, B., M. Maor, K. Levy, R. Kaspi, P. Taylor, and T. Shelly. 2007. Breakfast of champions or kiss of death? Survival and sexual performance of protein-fed, sterile Mediterranean fruit flies (Diptera: Tephritidae). Florida Entomologist 90: 115-122. https://doi.org/10.1653/0015-4040(2007)90[115:BOCOKO]2.0.CO;2

Yuval, B., E. Ben-Ami, A. Behar, M. Ben-Yosef, and E. Jurkevitch. 2013. The Mediterranean fruit fly and its bacteria - potential for improving sterile insect technique operations. Journal of Applied Entomology 137(S1): 39-42. http://onlinelibrary.wiley.com/doi/10.1111/j.1439-0418.2010.01555.x/full 
Zabalou, S., A. Apostolaki, I. Livadaras, G. Franz, A. S. Robinson, C. Savakis, and K. Bourtzis. 2009. Incompatible insect technique: incompatible males from a Ceratitis capitata genetic sexing strain. Entomologia Experimentalis et Applicata 132: 232-240. http://onlinelibrary.wiley.com/doi/10.1111/j.1570-7458.2009.00886.x/full

Zygouridis, N. E., Y. Argov, E. Nemny-Lavy, A. A. Augustinos, D. Nestel, and K. D. Mathiopoulos. 2014. Genetic changes during laboratory domestication of an olive fly SIT strain. Journal of Applied Entomology 138: 423-432. http://onlinelibrary.wiley.com/doi/10.1111/jen.12042/abstract 